Article

\title{
Evaluating Operational AVHRR Sea Surface Temperature Data at the Coastline Using Benthic Temperature Loggers
}

\author{
Robert J. W. Brewin ${ }^{1,2, *}$, Dan A. Smale ${ }^{3}{ }^{(0)}$, Pippa J. Moore ${ }^{4}$ (), Giorgio Dall'Olmo ${ }^{1,2}$, \\ Peter I. Miller ${ }^{1}{ }^{(1)}$, Benjamin H. Taylor ${ }^{1}$, Tim J. Smyth ${ }^{1}$, James R. Fishwick ${ }^{1}$ and Mingxi Yang ${ }^{1}$ \\ 1 Plymouth Marine Laboratory, Plymouth, Devon PL1 3DH, UK; gdal@pml.ac.uk (G.D.); \\ PIM@pml.ac.uk (P.I.M.); benj@pml.ac.uk (B.H.T.); TJSM@pml.ac.uk (T.J.S.); JRFI@pml.ac.uk (J.R.F.); \\ miya@pml.ac.uk (M.Y.) \\ 2 National Centre for Earth Observation, Plymouth Marine Laboratory, Plymouth, Devon, PL1 3DH, UK \\ 3 Marine Biological Association of the United Kingdom, The Laboratory, Plymouth, Devon PL1 2PB, UK; \\ dansma@MBA.ac.uk \\ 4 Institute of Biological, Environmental and Rural Sciences, Aberystwyth University, \\ Aberystwyth SY23 3DA, UK; pim2@aber.ac.uk \\ * Correspondence: robr@pml.ac.uk; Tel.: +44-1752-633-100
}

Received: 25 April 2018; Accepted: 2 June 2018; Published: 12 June 2018

Abstract: The nearshore coastal ocean is one of the most dynamic and biologically productive regions on our planet, supporting a wide range of ecosystem services. It is also one of the most vulnerable regions, increasingly exposed to anthropogenic pressure. In the context of climate change, monitoring changes in nearshore coastal waters requires systematic and sustained observations of key essential climate variables (ECV), one of which is sea surface temperature (SST). As temperature influences physical, chemical and biological processes within coastal systems, accurate monitoring is crucial for detecting change. SST is an ECV that can be measured systematically from satellites. Yet, owing to a lack of adequate in situ data, the accuracy and precision of satellite SST at the coastline are not well known. In a prior study, we attempted to address this by taking advantage of in situ SST measurements collected by a group of surfers. Here, we make use of a three year time-series (2014-2017) of in situ water temperature measurements collected using a temperature logger (recording every $30 \mathrm{~min}$ ) deployed within a kelp forest ( $\sim 3 \mathrm{~m}$ below chart datum) at a subtidal rocky reef site near Plymouth, UK. We compared the temperature measurements with three other independent in situ SST datasets in the region, from two autonomous buoys located $\sim 7 \mathrm{~km}$ and $\sim 33 \mathrm{~km}$ from the coastline, and from a group of surfers at two beaches near the kelp site. The three datasets showed good agreement, with discrepancies consistent with the spatial separation of the sites. The in situ SST measurements collected from the kelp site and the two autonomous buoys were matched with operational Advanced Very High Resolution Radiometer (AVHRR) EO SST passes, all within $1 \mathrm{~h}$ of the in situ data. By extracting data from the closest satellite pixel to the three sites, we observed a significant reduction in the performance of AVHRR at retrieving SST at the coastline, with root mean square differences at the kelp site over twice that observed at the two offshore buoys. Comparing the in situ water temperature data with pixels surrounding the kelp site revealed the performance of the satellite data improves when moving two to three pixels offshore and that this improvement was better when using an SST algorithm that treats each pixel independently in the retrieval process. At the three sites, we related differences between satellite and in situ SST data with a suite of atmospheric variables, collected from a nearby atmospheric observatory, and a high temporal resolution land surface temperature (LST) dataset. We found that differences between satellite and in situ SST at the coastline (kelp site) were well correlated with LST and solar zenith angle; implying contamination of the pixel by land is the principal cause of these larger differences at the coastline, as opposed to issues with atmospheric correction. This contamination could be 
either from land directly within the pixel, potentially impacted by errors in geo-location, or possibly through thermal adjacency effects. Our results demonstrate the value of using benthic temperature loggers for evaluating satellite SST data in coastal regions, and highlight issues with retrievals at the coastline that may inform future improvements in operational products.

Keywords: sea surface temperature; thermal radiometry; remote sensing; validation; coastline

\section{Introduction}

The nearshore coastal ocean, defined here as the intertidal, subtidal and nearshore zones (typically within a kilometre of the shoreline), is among the most temporally and spatially variable regions on our planet, with cyclic variations from seconds to decades and wide geographical differences [1,2]. Coastal marine ecosystems provide a range of ecological goods and services, including biodiversity maintenance [3], habitat provision for important species [4], and carbon cycling and sequestration [5]. However, with more than half the world's human population living in coastal regions [6], many nearshore marine ecosystems are impacted by multiple anthropogenic stressors, including decreased water quality [7,8], overfishing [9] and habitat loss [10]. Additionally, at regional scales, the combined impacts of climate change-ocean warming, sea-level rise and acidification-are altering coastal marine ecosystems [11,12].

Monitoring the nearshore coastal ocean is key to understanding how it is responding to threats. In the context of climate change, systematically monitoring essential climate variables (ECV), one of which is ocean temperature (both at the surface and subsurface), is vital for coastal management $[13,14]$. Sea surface temperature (SST) is considered by the Global Climate Observing System as an ECV [14,15], and described in the 5th Assessment Report (AR5) of the Intergovernmental Panel on Climate Change (IPCC) as a key driver of climate change impacting coastal systems [16]. Temperature influences coastal ocean physics e.g., through changes in water density [17], ecology [18-21] and marine chemistry [22,23]. With specific regards to marine ecosystems, recent warming trends have been linked with shifts in species distributions [24] and consequent reconfigurations of communities [25], while discrete extreme warming events have driven widespread changes in ecosystem structure across large spatial scales [26,27].

Traditional methods for measuring sea temperature data (e.g., using research vessels, autonomous platforms or buoys) are not well suited to nearshore systems, owing to their shallow, energetic and dynamic environment. Thermal and microwave based remote-sensing systems are increasingly being used in coastal oceanography, from satellite, aircraft and fixed platforms. Satellite remote-sensing is capable of providing SST with high spatial coverage and good temporal resolution, providing adequate in situ observations are available for algorithm calibration and for quantifying the accuracy and precision of the satellite SST retrievals, essential for any application. Owing to a large network of in situ instruments on a variety of platforms, our understanding of the accuracy and precision of the satellite SST retrievals is reasonable in the open ocean [28]. However, in the nearshore coastal ocean, it is poor, due to sparse and insufficient in situ datasets being available [29,30].

To address this, Brewin et al. [30] recently utilised in situ SST measurements collected from a group of recreational surfers and matched these observations in time and space with satellite SST retrievals from the Advanced Very High Resolution Radiometers (AVHRR) series. They found a significant reduction in the performance of AVHRR algorithms at retrieving SST at the coastline, with root mean square differences over twice that observed from validations using buoy data a few kilometres offshore. Although there is remarkable potential for using surfers and other watersports participants for improving data collection in the nearshore coastal ocean [31-35], currently such datasets are relatively sparse and limited to conditions preferable for the activity, such that the findings of Brewin et al. [30] were based on a relatively limited number of satellite and in situ match-ups. 
In recent years, marine ecologists interested in the physiology and ecology of coastal organisms, such as habitat-forming seaweeds, have collected in situ temperature data at high temporal resolution from various shallow subtidal habitats [36,37]. Typically, temperature loggers have been deployed on the sea bed at $\sim 3-15 \mathrm{~m}$ below chart datum, deeper than water temperature measurements commonly used in satellite validation studies, where they record temperature continuously over long periods of time. In situ benthic temperature data have also been compared with satellite SST datasets [38,39]. However, as the goals of these studies were to investigate the use of satellite SST data as a proxy for nearshore benthic water temperature, rather than for satellite validation, these comparisons were conducted using SST data at a relatively coarse spatial resolution (e.g., using a $20 \mathrm{~km}^{2}$ box located around the site) and often averaged in time (e.g., over a 4 to 10 day period), rather than data close to the native resolution of the satellite (typically $1 \mathrm{~km}$ ) and within a strict time window of the satellite pass (e.g., \pm 1 to $3 \mathrm{~h}$ ), as typically undertaken in satellite validation exercises e.g., [30,40].

In this study, we make use of high temporal resolution in situ water temperature measurements collected using a benthic temperature logger in a subtidal kelp forest near Plymouth, UK, to evaluate operational AVHRR SST data at the coastline. To determine if temperature data from the benthic logger is useful as a proxy for SST, we compared the measurements with three other independent in situ SST datasets in the region, from a group of surfers collected at two beaches near the location of the kelp site, and from two autonomous buoys located $\sim 7 \mathrm{~km}$ and $\sim 33 \mathrm{~km}$ from the coastline of Plymouth. The in situ SST measurements collected from the kelp site and the two autonomous buoys were matched with AVHRR passes (closest $1 \mathrm{~km}$ pixel) all within $1 \mathrm{~h}$ of the satellite passes. We then related differences between satellite and in situ data to a suite of atmospheric variables, collected from a nearby atmospheric observatory, and to a high temporal resolution land surface temperature (LST) dataset, to highlight key issues impacting satellite SST retrievals at the coastline that may inform future improvements in the satellite products.

\section{Methods}

\subsection{Study Site: Plymouth, United Kingdom}

The chosen study site was the coastal and offshore waters of Plymouth in the UK (Figure 1a). Plymouth is an ideal location for evaluating satellite SST data as it hosts a suite of in situ datasets, including: data from two oceanographic stations (Station L4 and E1) where autonomous buoys are operated, which form part of the Western Channel Observatory (http:/ / www.westernchannelobservatory.org.uk/) run by Plymouth Marine Laboratory (PML) and the Marine Biological Association of the UK (MBA); the Penlee Point Atmospheric Observatory (Figure 1a), also run by PML, routinely collecting atmospheric data; a time-series of SST measurements collected at the coastline voluntarily by surfers [30,31]; and a time-series of water temperature measurements collected at a long-term kelp forest study site [37].

To place our study site in a global and regional context, it spans an area of approximately $1582 \mathrm{~km}^{2}$ (Figure 1a). The surface water temperature surrounding Plymouth varies seasonally between 8 and $20{ }^{\circ} \mathrm{C}$ [30,37], a relatively wide range that is useful for evaluating satellite datasets. These waters support a wide range of ecosystem services [41], they have been increasingly exposed to anthropogenic impacts like eutrophication [42], and have been warming with climate change [43], all of which has implications for regional marine productivity and biodiversity e.g., [44-46]. 

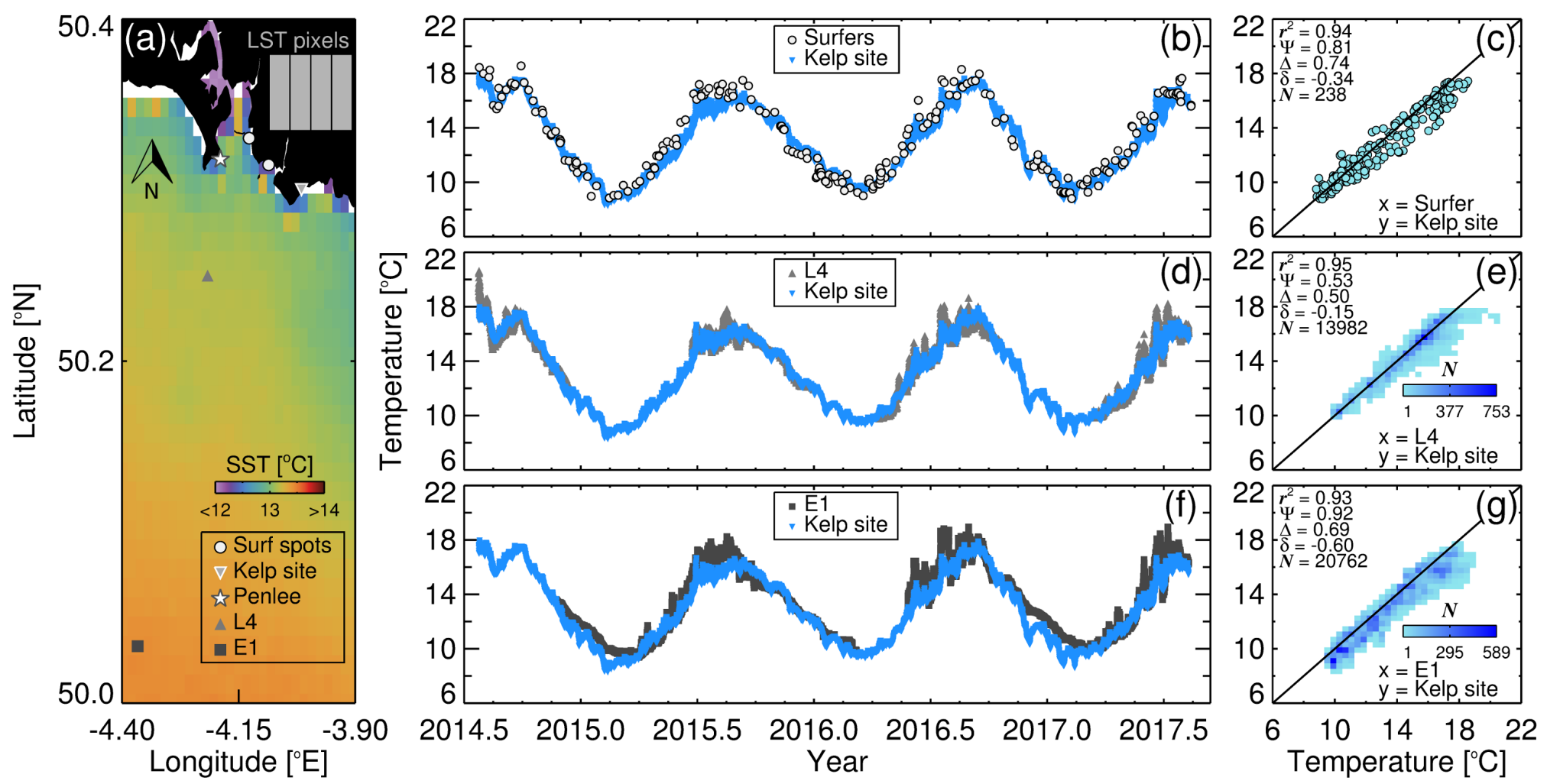

Figure 1. Comparison of in situ temperature data from the kelp site with three independent sea surface temperature (SST) datasets near Plymouth, UK. (a) locations of the kelp site, surfing data collected at the two beaches (Wembury and Bovisand), Station L4, Station E1, the Penlee Atmospheric Observatory, and the location of satellite pixels from a high temporal resolution time-series of Land Surface Temperature (LST) data acquired from the Copernicus Global Land Service. The background is a three-year mean composite of AVHRR satellite SST ${ }_{N}$ data from July 2014 to June 2017. (b) time-series of SST acquired by the surfers at the two beaches overlain onto the kelp site temperature data; (c) scatter plots of match-ups (within $\pm 1 \mathrm{~h}$ ) between SST acquired by the surfer at the beaches and temperature data from the kelp site; (d) time-series of kelp site temperature data overlain onto the SST data from Station L4; (e) scatter plots of match-ups (within $\pm 1 \mathrm{~h}$ ) between SST at L4 and temperature data from the kelp site; (f) time-series of kelp site temperature data overlain onto the SST data from Station E1; (g) scatter plots of match-ups (within $\pm 1 \mathrm{~h}$ ) between SST at E1 and temperature data from the kelp site. $r^{2}$ is the coefficient of determination, $\Psi$ the root mean square error, $\delta$ the bias, $\Delta$ the centre-pattern (or unbiased) root mean square error, and $N$ the number of match-ups. 


\subsection{Statistical Tests}

We used the following univariate statistical tests, often used in comparisons between satellite and in situ data e.g., [30,47,48], to compare estimates of temperature from two sources: the coefficient of determination or the squared Pearson correlation coefficient $\left(r^{2}\right)$; the absolute Root Mean Square Difference $(\Psi)$; absolute bias between the estimated and measured variable $(\delta)$; and the absolute centre-pattern (or unbiased) Root Mean Square Difference $(\Delta)$. We also used the Pearson correlation coefficient $(r)$ when investigating correlations in the differences between satellite and in situ data and other environmental variables. The equations used to compute each statistic are provided in Appendix A.

\subsection{In Situ Temperature Datasets and Auxiliary Measurements}

\subsubsection{Kelp Site Water Temperature Measurements}

Between July 2014 and August 2017, a UTBI-001 Tidbit v2 Temperature Data Logger was deployed and maintained on a kelp covered reef at a depth of $\sim 3 \mathrm{~m}$ below chart datum, $\sim 10 \mathrm{~km}$ from Plymouth, UK (Figure 1a, latitude $=50.300164^{\circ} \mathrm{N}$, longitude $=-4.01514^{\circ} \mathrm{E}$ ). Manufacturers report an accuracy of $0.2{ }^{\circ} \mathrm{C}$ over a range of 0 to $50{ }^{\circ} \mathrm{C}$, a resolution of $\sim 0.02{ }^{\circ} \mathrm{C}$ at $25^{\circ} \mathrm{C}$, a stability of $\sim 0.1{ }^{\circ} \mathrm{C}$ per year, and a response time of $5 \mathrm{~min}$ in water, for the Tidbit v2 sensors. Brewin et al. [30] have tested the performance of these sensors in laboratory conditions every six months over a three-year period, by comparing the sensors with a VWR1620-200 traceable digital thermometer (NIST/ISO calibrated, accuracy of $0.05{ }^{\circ} \mathrm{C}$ and a resolution of $0.001{ }^{\circ} \mathrm{C}$ ) from 6 to $25^{\circ} \mathrm{C}$ using a PolyScience temperature bath. They found all Tidbit v2 sensors performed within the manufacturers' technical specifications, with systematic differences (biases) and root mean square differences $<0.15^{\circ} \mathrm{C}$. When considering space agencies target accuracy requirements for state-of-the-art satellite thermal sensors in coastal waters are $<0.5^{\circ} \mathrm{C}$ [49], these Tidbit sensors were deemed suitable for evaluating satellite SST retrievals in coastal waters.

The Tidbit v2 data logger was set to record water temperature every 30 min. Every 6-12 months over the duration of the study, the data logger was retrieved by scuba divers and data were uploaded using HOBOware software (version 3.7.12), and HOBO USB Optic Base Station (BASE-U-4) onto a laptop; then, the logger was relaunched and reattached by scuba divers at the same location. This provided a continuous time-series of water temperature measurements at the kelp site over the study period at 30 min intervals (Figure $1 b$ ).

\subsubsection{SST Measurements Collected by Surfers at the Coastline}

For comparison with temperature data at the kelp site, we made use of a time-series of sea surface temperature measurements collected by surfers $[30,31]$ over the same time-period at two beaches near the kelp site (Figure 1a), Wembury Beach (latitude $=50.316^{\circ} \mathrm{N}$, longitude $=-4.085^{\circ} \mathrm{E}$ ) and Bovisand Beach (latitude $=50.332^{\circ} \mathrm{N}$, longitude $=-4.122^{\circ} \mathrm{E}$ ). The data were processed following the methods described in Brewin et al. [30]. Briefly, the surfers were equipped with the same data loggers used at the kelp site (Tidbit v2 data logger) and a GARMIN GPS logger (eTrex 10). The Tidbit v2 data loggers were calibrated against a VWR1620-200 traceable digital thermometer in the laboratory every six months, and a piecewise regression model was used to correct any systematic differences $(\delta)$ among sensors as a function of time, correcting all sensors used to the VWR1620-200 traceable digital thermometer. HOBOware software and HOBO USB Optic Base Station (BASE-U-4) were used by the surfer to launch the Tidbit v2 temperature logger prior to each session, and then, to upload the data post session (see [30]). Temperature data were collected at $1 / 10 \mathrm{~Hz}$ during each surf. Both temperature and GPS data were processed to remove measurements collected before and after each surf session, and the median of the remaining data were computed to derive the median temperature and GPS location during each surfing session, as well as the mid-point of the session in time, which was typically $1 \mathrm{~h}$ long. For additional information on this dataset, see Brewin et al. [30,31]. 


\subsubsection{SST from Station L4 and E1}

For comparison with data from the kelp site and satellite SST observations offshore from the coastline, we made use of SST data from two oceanographic stations in the Western Channel Observatory (WCO): Station L4 (latitude $=50.250^{\circ} \mathrm{N}$, longitude $=-4.217^{\circ} \mathrm{E}$ ) located $\sim 7 \mathrm{~km}$ from the coastline and Station E1 (latitude $=50.033^{\circ} \mathrm{N}$, longitude $=-4.367^{\circ} \mathrm{E}$ ) located $\sim 33 \mathrm{~km}$ from the coastline (Figure 1a). At both stations, an autonomous buoy is operated equipped with a Sea-Birds Conductivity Temperature and Depth (CTD) sensor (accuracy of $0.002{ }^{\circ} \mathrm{C}$ at a range of -5 to $35{ }^{\circ} \mathrm{C}$, resolution of $0.001{ }^{\circ} \mathrm{C}$ ) mounted on a marine-grade stainless steel cage and situated in a moon pool (an opening in the floatation) measuring SST at a fixed depth of $1 \mathrm{~m}$. The SST is recorded at hourly intervals, with some gaps in the datasets from buoy maintenance and downtime. Details on the operation of these autonomous buoy systems can be found in Smyth et al. [50]. Datasets on SST were downloaded from the Western Channel Observatory website (http:/ / www.westernchannelobservatory.org.uk/data/buoy/) between July 2014 and August 2017 (Figure 1d,f).

\subsubsection{Observations at Penlee Point Atmospheric Observatory}

To estimate SST from a satellite radiometer, the brightness temperatures in two or more thermal channels are used (see Section 2.4). Differences between two or more bands are used to correct for the atmosphere. The main atmospheric constituent that impacts thermal bands is water vapor, which varies highly in both space and time [51]. In open-ocean regions, other molecular species that contribute to the temperature deficit are generally quite well-mixed throughout the atmosphere, and therefore cause a relatively constant temperature deficit that is easier to correct for [51]. At the coastline, however, this may not be the case. Increased complexity in the atmosphere at the coastline may challenge satellite retrievals of SST.

To investigate this, we made use of atmospheric observations collected at the Penlee Point Atmospheric Observatory (http:/ / www.westernchannelobservatory.org.uk/penlee/) (Figure 1a, $50.318^{\circ} \mathrm{N},-4.18917^{\circ} \mathrm{E}$ ), roughly $13 \mathrm{~km}$ from the kelp site, $8 \mathrm{~km}$ from Station $\mathrm{L} 4$, and $34 \mathrm{~km}$ from Station E1 (Figure 1a). The observatory was established in May 2014 and has collected continuous measurements (every $5 \mathrm{~min}$ ) of various meteorological variables, including: wind speed, wind direction, air temperature, humidity, pressure, $\mathrm{CO}_{2}, \mathrm{SO}_{2}$ and $\mathrm{CH}_{4}$, among others. For additional information on the Penlee Point Atmospheric Observatory and additional details on how these measurements were taken, see Yang et al. [52,53].

\subsubsection{Land Surface Temperature Data}

In addition to investigating the impact of atmospheric observations on satellite SST retrievals at the coastline, we also investigated the impact of land surface temperature (LST), caused either by land directly within the pixel or through thermal adjacency effects. To do this, we downloaded a hourly LST dataset from the Copernicus Global Land Service (https:/ /land.copernicus.eu/global/products/lst), for the period of July 2014 to August 2017. The LST is the radiative skin temperature of the land surface measured from Top-of-Atmosphere brightness temperatures in the infrared spectral channels of a constellation of geostationary satellites (Meteosat Second Generation, GOES, MTSAT/Himawari). Its computation depends on estimations of albedo, the vegetation cover and soil moisture. In addition to using a LST thermal dataset independent of AVHRR, this high temporal resolution product (hourly) also allowed us to investigate differences between in situ SST between nearshore (kelp site) and offshore (Station L4) waters at a high temporal resolution. Data from four pixels located close to the kelp site were extracted (Figure 1a), with the median of the four pixels used as an index of LST. 


\subsection{Satellite SST Datasets}

Two operational AVHRR SST datasets were acquired through the UK Natural Environmental Research Council (NERC) Earth Observation Data Acquisition and Analysis Service (NEODAAS (http:/ /www.neodaas.ac.uk/)). The AVHRR sits on-board the National Oceanic and Atmospheric Administration (NOAA) sun synchronous family of Polar Orbiting Environmental Satellites (POES). It is a scanning sensor with a relatively wide swath $(\sim 2400 \mathrm{~km})$ that views the same location roughly twice a day (depending on latitude). The AVHRR measures emitted thermal radiation at a number of bands, two of which (at 11 and 12 micrometers) are principally used to derive SST. We made use of two platforms that operate the AVHRR, NOAA-19 and MetOp-B, which were capable of providing up to four views of the same location in a single day.

The NEODAAS operational processing system is described in detail in Miller et al. [54] (see also [30]). Briefly, a receiving station located in Dundee (http:/ / www.sat.dundee.ac.uk) acquires High Resolution Picture Transmission (HRPT) passes over NW Europe and the Arctic. These passes are then transmitted, via a fast internet link, to Plymouth Marine Laboratory for processing. The HRPT images are then processed to Level 3, involving: georeferencing, using an orbital model together with ephemeris data from NOAA [55] and an automated navigation adjustment that matches image features with a database of ground control points [56]; generation of a land mask using the University of Hawaii's Generic Mapping Tools (http:/ /gmt.soest.hawaii.edu/), which is then overlaid on the georectified AVHRR image; application of a hybrid cloud mask, adapted from Saunders and Kriebel [57], Thiermann and Ruprecht [58], Roozekrans and Prangsma [59]; and application of a cloud proximity test to minimise cloud-edge effects and sub-pixel cloud contamination [54]. Two operational AVHRR algorithms are available for implementation that were used in this study, the standard NOAA method, a nonlinear SST (denoted here as SST $_{N}$ ) split-window equation using infrared channels 4 and 5 (at 11 and 12 micrometers) that is expressed as

$$
\mathrm{SST}_{N}=b_{0}+b_{1} T_{i}+b_{2}\left(T_{i}-T_{j}\right) \mathrm{SST}_{r}+b_{3}\left(T_{i}-T_{j}\right)(\sec \theta-1),
$$

where $b_{0}$ through to $b_{3}$ are empirical coefficients, $T_{i}$ and $T_{j}$ refer to channels 4 and 5 (at 11 and 12 micrometers), respectively, SST $_{r}$ is a reference SST (first-guess SST) and $\theta$ is the zenith angle to the satellite radiometer, measured at the sea surface [51,60]. A second approach that is used by NEODAAS is a modification called a partial SST method (denoted here as $\mathrm{SST}_{P}$ ) proposed by Barton [61] and adapted by Miller et al. [54]. This involves splitting the standard SST equation into "sea" and "atmosphere" components, where

$$
\operatorname{SST}_{P}=T_{i}+\left[\left(\mathrm{SST}_{N}-T_{i}\right) H\right]
$$

where $T_{i}$ (channels 4 ) is assumed to be the temperature signal from the sea surface, $\mathrm{SST}_{N}-T_{i}$ is the drop in brightness temperature attributable to water vapour absorption, and $\mathrm{SST}_{P}$ is the sum of the two components after convolving the atmosphere image with a smoothing filter $(H)$, with a window size of $17.5 \mathrm{~km}$ square. This technique assumes that water vapour varies on larger scales than SST, and is independent of SST over small areas. It was developed as a trade-off between noise reduction and structure blurring, with the goal of creating an improvement in the appearance of SST images [54]. It is worth recognising that the $\mathrm{SST}_{P}$ method was not originally developed for retrievals of SST at the coastline.

Once the algorithms are implemented, the images are transformed to Mercator projection $(\sim 1 \mathrm{~km}$ resolution), using the MODIS Swath-to-Grid Toolbox (MS2GT). Individual satellite passes were used in this study, so we could match with the in situ data within a given time window. These Level 3 mapped scenes were acquired from NEODAAS between July 2014 and August 2017, providing $\mathrm{SST}_{P}, \mathrm{SST}_{N}$, latitude and longitude data for each pixel in the scene, and the time (GMT) of the overpass. We also produced a three-year mean composite image of all $\mathrm{SST}_{N}$ satellite passes from July 2014 to June 2017, 
by averaging all $\mathrm{SST}_{N}$ passes in a given month to produce monthly composites; then, all monthly composites were averaged to derive a three-year mean composite image (Figure 1a).

\subsection{Comparison of Datasets}

\subsubsection{Comparison of In Situ Datasets}

To inspect whether water temperature measurements from the kelp site could be used for evaluating satellite observations of SST, we first compared data from the kelp site with three other in situ datasets in the region, SST measurements collected by surfers from two nearby beaches in Plymouth (Wembury Beach and Bovisand Beach), and SST measurements collected at Station L4 and at Station E1. This comparison was conducted quantitatively, by matching (with a time difference of $\leq 1 \mathrm{~h}$ ) co-incident SST measurements and applying statistical tests described in Section 2.2, and qualitatively, by overlaying the SST time-series from the kelp site onto each independent dataset.

\subsubsection{Comparisons of Satellite and In Situ Datasets}

A time-series of all Level 3 AVHRR SST $P$ and $\operatorname{SST}_{N}$ satellite passes were extracted for the region surrounding Plymouth, covering longitudes from -4.5 to $-3.6^{\circ} \mathrm{E}$ and latitudes from 49.9 to $50.5^{\circ} \mathrm{N}$. We first matched the closest ocean pixel to the three sites where continuous in situ data were available, at the kelp site, at Station L4 and at Station E1 (see Figure 2a). The satellite datasets were overlaid onto the in situ datasets to qualitatively compare the two data sources (see Figure $2 b, d, f$ ). We then selected all satellite data at the closest ocean pixel within $\pm 1 \mathrm{~h}$ of the in situ data, and quantitatively evaluated the performance of AVHRR $\mathrm{SST}_{P}$ and $\mathrm{SST}_{N}$ datasets at the three locations using statistical tests described in Section 2.2 (see Figure 2c,e,g and Table 1). Next, we repeated this same exercise for all pixels in the entire region surrounding Plymouth at all three sites, and produced maps of these statistics (i.e., match-ups within $\pm 1 \mathrm{~h}$ of the in situ data) to visualise the spatial variability in the agreement between satellite and the in situ data (see Figures 3 and 4).

For all match-ups within $\pm 1 \mathrm{~h}$, for the closest pixel to each site, we compared the difference between satellite $\left(\mathrm{SST}_{N}\right)$ and in situ SST data with a suite of auxiliary data matched within $1 \mathrm{~h}$ of the satellite overpass. This included: air temperature, SST - air temperature, relative humidity, air pressure, wind speed, wind direction, $\mathrm{CO}_{2}, \mathrm{SO}_{2}, \mathrm{CH}_{4}$, LST, LST-SST and air temperature-LST, available from the Penlee Point Atmospheric Observatory and from the Copernicus Global Land Service LST dataset. We also compared the difference between satellite $\left(\mathrm{SST}_{N}\right)$ and in situ SST data with time of year, hour of day, and solar zenith angle, the latter computed as a function of date and position at the three sites (see Figure 5 and Table 2).

Next, we computed the difference in SST between the kelp site and L4 using the in situ and satellite $\left(\mathrm{SST}_{N}\right)$ datasets separately, and compared these differences with hour of the day, solar zenith angle and LST (see Figure 6). For a group of pixels surrounding the kelp site, we then computed systematic differences $(\delta)$ between satellite and in situ SST data for day and night time overpasses separately (see Figure 7a-c). Finally, we correlated the difference between satellite $\left(\mathrm{SST}_{N}\right)$ and in situ SST data at the kelp site with solar zenith angle, LST and LST-SST, on a per-pixel basis for a group of pixels surrounding the kelp site (see Figure $7 \mathrm{~d}-\mathrm{f}$ ). 

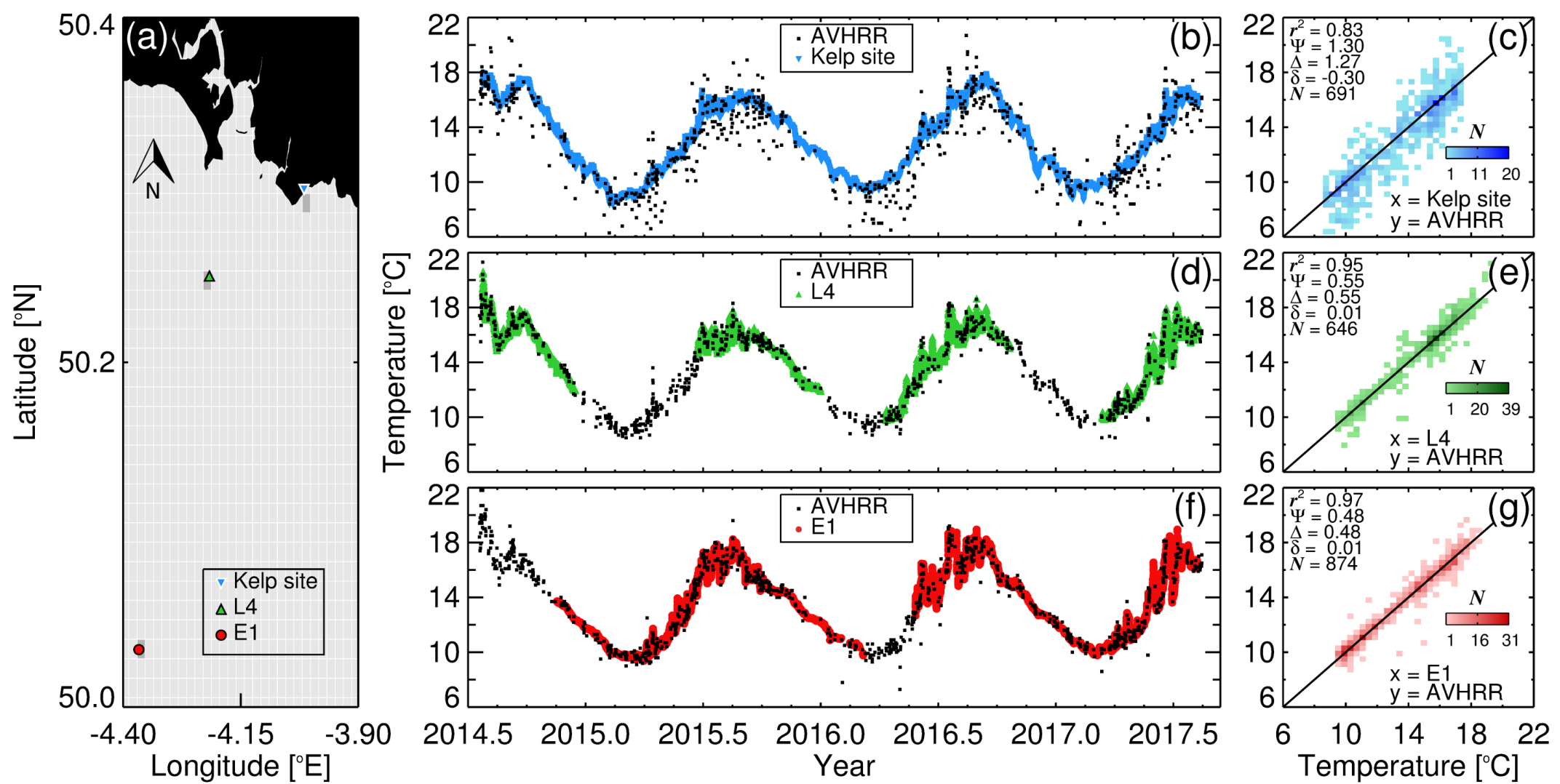

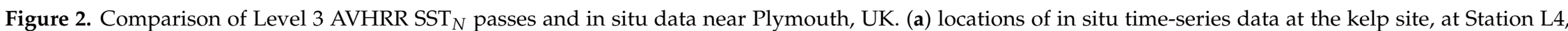
at Station E1, and the closest pixels selected from the AVHRR mapped Level 3 passes to be representative of the three locations (dark grey pixels); (b) time-series of AVHRR SST $_{N}$ passes for the pixel closest to the kelp site overlain onto in situ temperature data from the kelp site; (c) scatter plots of match-ups (within $\pm 1 \mathrm{~h}$ ) between

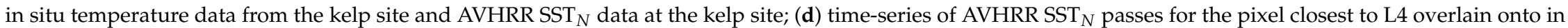
situ SST at L4; (e) scatter plots of match-ups (within $\pm 1 \mathrm{~h}$ ) between SST acquired in situ and by AVHRR at L4; (f) time-series of AVHRR SST ${ }_{N}$ passes for the pixel closest to E1 overlain onto in situ SST at E1; (g) scatter plots of match-ups (within $\pm 1 \mathrm{~h}$ ) between SST acquired in situ and by AVHRR at E1. $r^{2}$ is the coefficient of determination, $\Psi$ the root mean square error, $\delta$ the bias, $\Delta$ the centre-pattern (or unbiased) root mean square error, and $N$ the number of match-ups. 


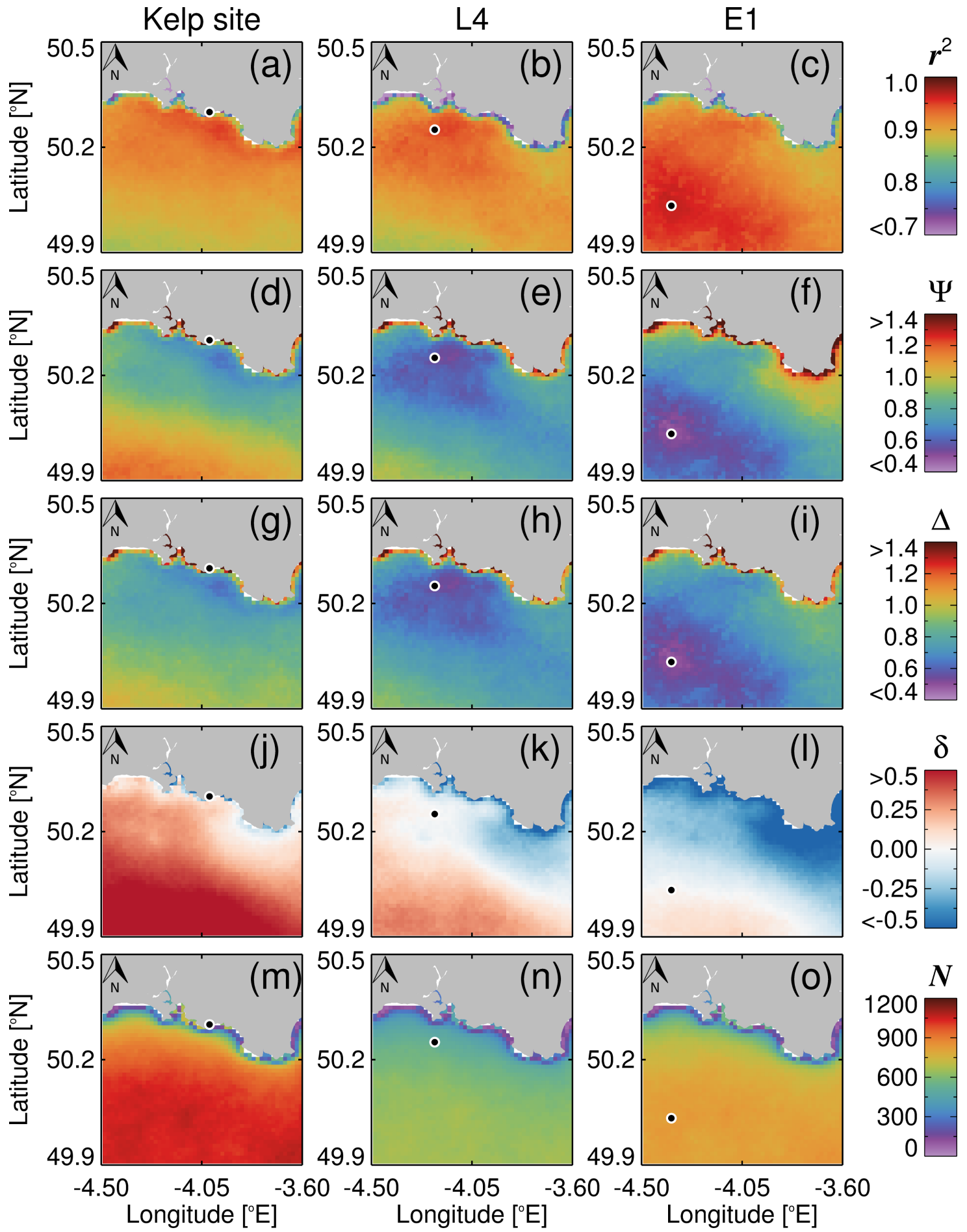

Figure 3. Spatial maps of statistical tests for match-ups within $\pm 1 \mathrm{~h}$ of in situ data for all AVHHR SST $N$ pixels within longitude -4.5 to $-3.6^{\circ} \mathrm{N}$ and latitude 49.9 to $50.5^{\circ} \mathrm{N}$. (a,d, $\left., \mathbf{g}, \mathbf{j}, \mathbf{m}\right)$ show match-ups for the kelp site, $(\mathbf{b}, \mathbf{e}, \mathbf{h}, \mathbf{k}, \mathbf{n})$ at Station L4 and $(\mathbf{c}, \mathbf{f}, \mathbf{i}, \mathbf{l}, \mathbf{o})$ at Station E1. $(\mathbf{a}-\mathbf{c})$ is the coefficient of determination $\left(r^{2}\right),(\mathbf{d}-\mathbf{f})$ the root mean square error $(\Psi),(\mathbf{g}-\mathbf{i})$ the centre-pattern (or unbiased) root mean square error $(\Delta),(\mathbf{j}-\mathbf{l})$ the bias $(\delta)$, and $(\mathbf{m}-\mathbf{o})$ the number of match-ups $(N)$. 

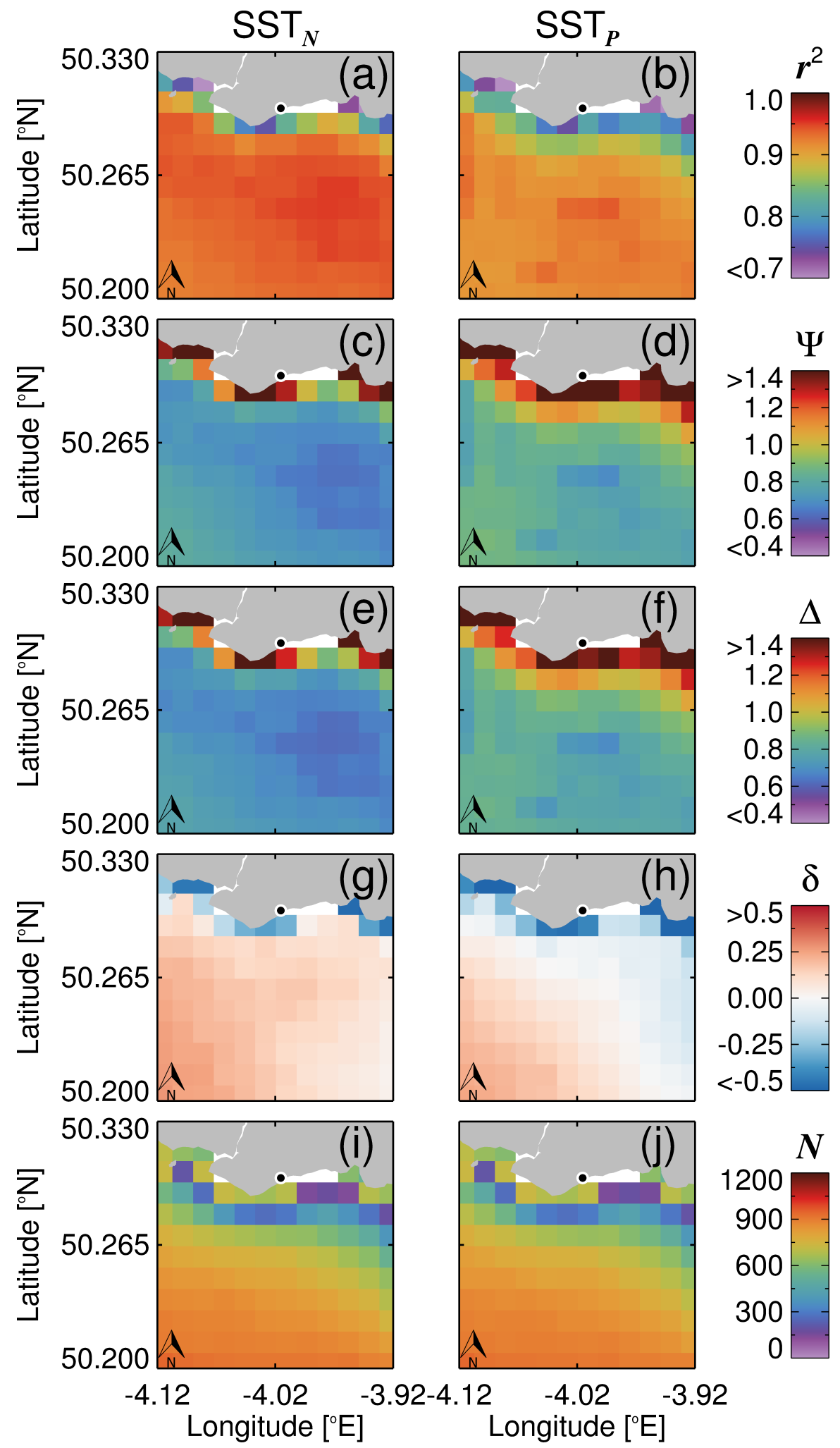

Figure 4. Spatial maps of statistical tests for match-ups within $\pm 1 \mathrm{~h}$ of kelp site in situ data for all AVHHR pixels ( $\mathrm{SST}_{N}$ and $\mathrm{SST}_{P}$ products) within longitude -4.12 to $-3.92^{\circ} \mathrm{E}$ and latitude 50.2 to $50.33^{\circ}$ N. (a,c,e, $\left.\mathbf{g}, \mathbf{i}\right)$ Show match-ups for the kelp site using $\operatorname{AVHHR~SST~}_{N}$ data, $(\mathbf{b}, \mathbf{d}, \mathbf{f}, \mathbf{h}, \mathbf{j})$ show

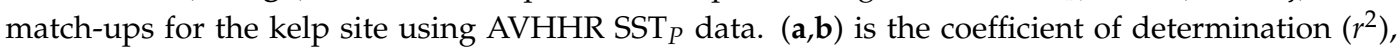
$(\mathbf{c}, \mathbf{d})$ the root mean square error $(\Psi),(\mathbf{e}, \mathbf{f})$ the centre-pattern (or unbiased) root mean square error $(\Delta)$, $(\mathbf{g}, \mathbf{h})$ the bias $(\delta)$, and $(\mathbf{i}, \mathbf{j})$ the number of match-ups $(N)$. 


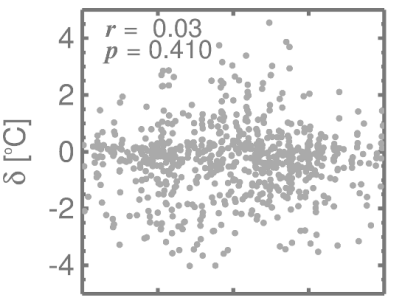

$\begin{array}{lllll}0.00 & 0.25 & 0.50 & 0.75 & 1.00\end{array}$ Decimal time of Year
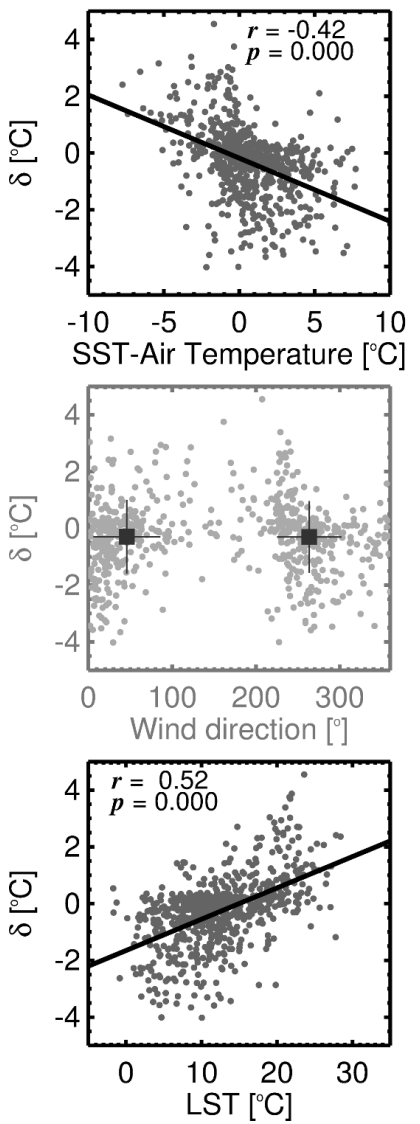
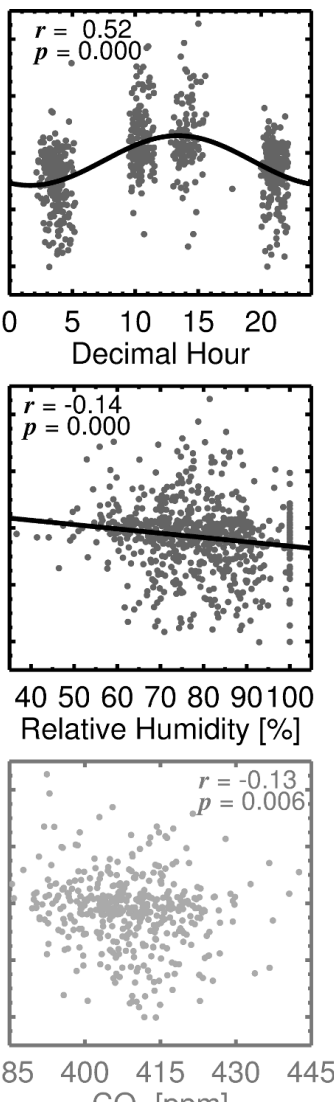
$\mathrm{CO}_{2}[\mathrm{ppm}]$

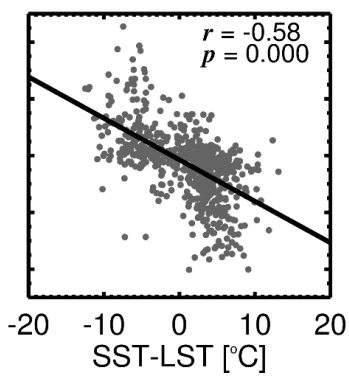

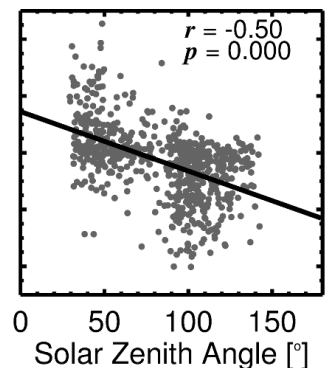
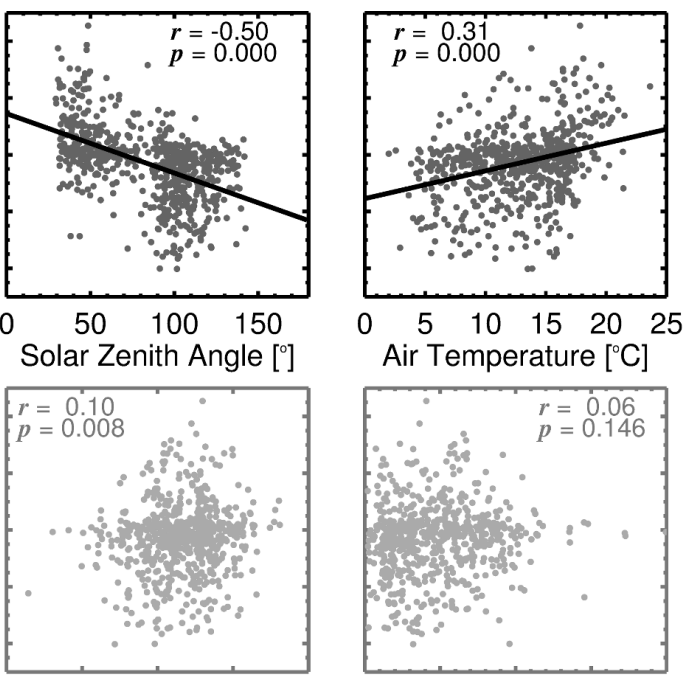

9809961012102910450 Air Pressure [mbar]
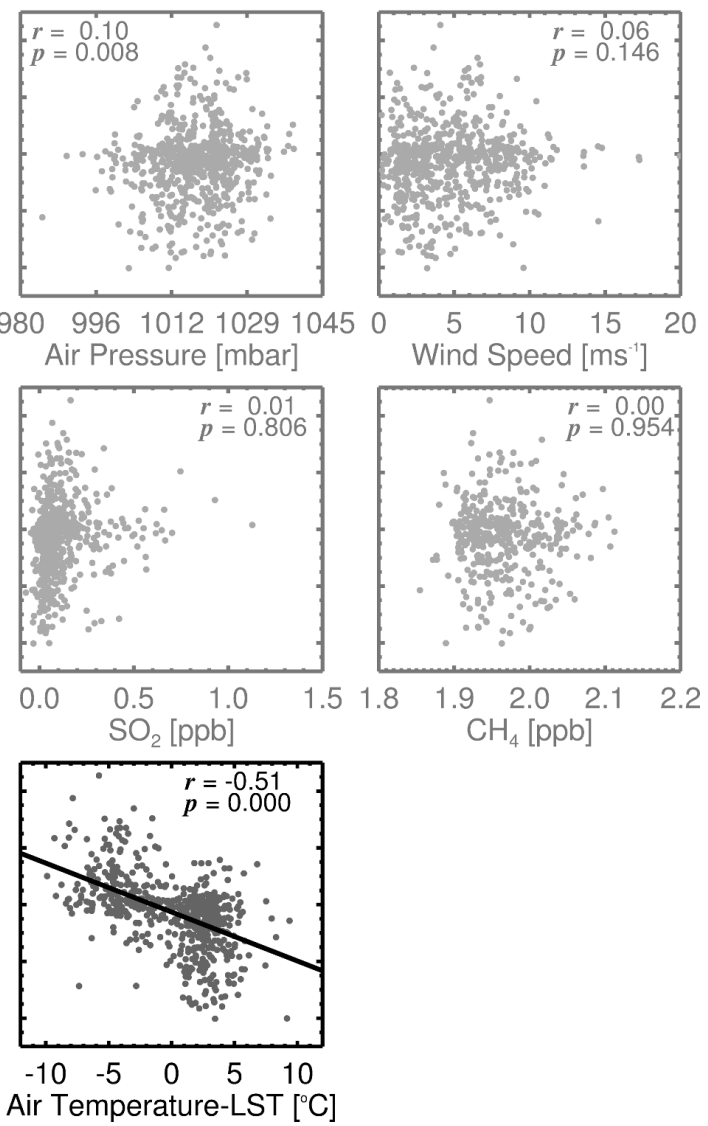

Figure 5. Differences between satellite AVHRR $\operatorname{SST}_{N}$ data at the closest pixel to the kelp site and in situ temperature from the kelp site $(\delta)$ as a function of a variety of variables. Bold plots show where there is a significant relationship (correlation between fit (linear or nonlinear) and data with a $p$-value $<0.001$ ). For the wind direction, we partitioned data into $0-180^{\circ}$ and $180-360^{\circ}$ and computed mean values and confidence intervals (both overlapped indicating no significant relationship between the two dominate wind directions, southwest and northeast). $r$ is the Pearson correlation coefficient and $p$ is the significance of this correlation. 

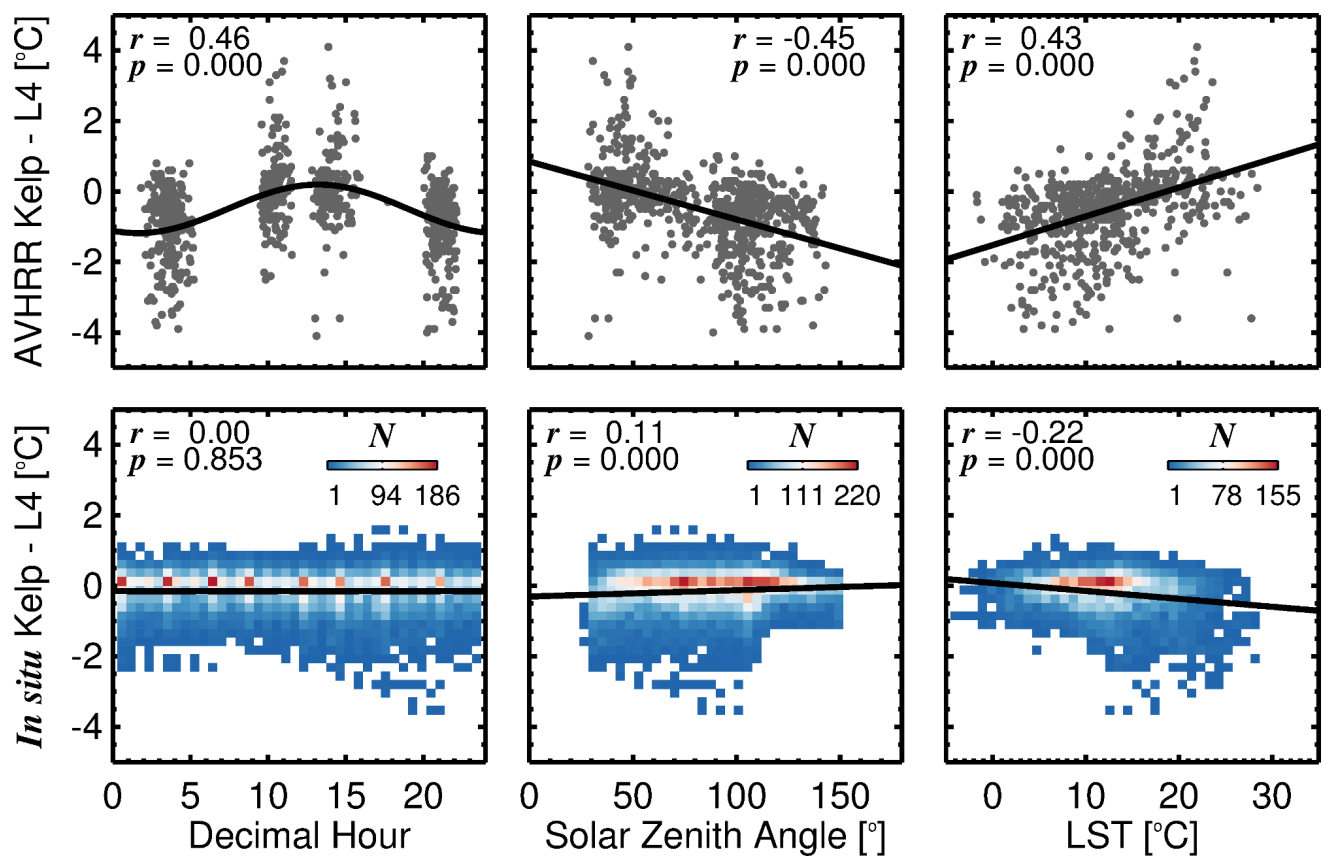

Figure 6. Differences between temperature data at the kelp site and at Station L4, as a function of decimal hour of day, solar zenith angle and Land Surface Temperature (LST), from AVHRR SST $N$ (top row) and for in situ data (bottom row). $r$ is the Pearson correlation coefficient and $p$ is the significance of this correlation.
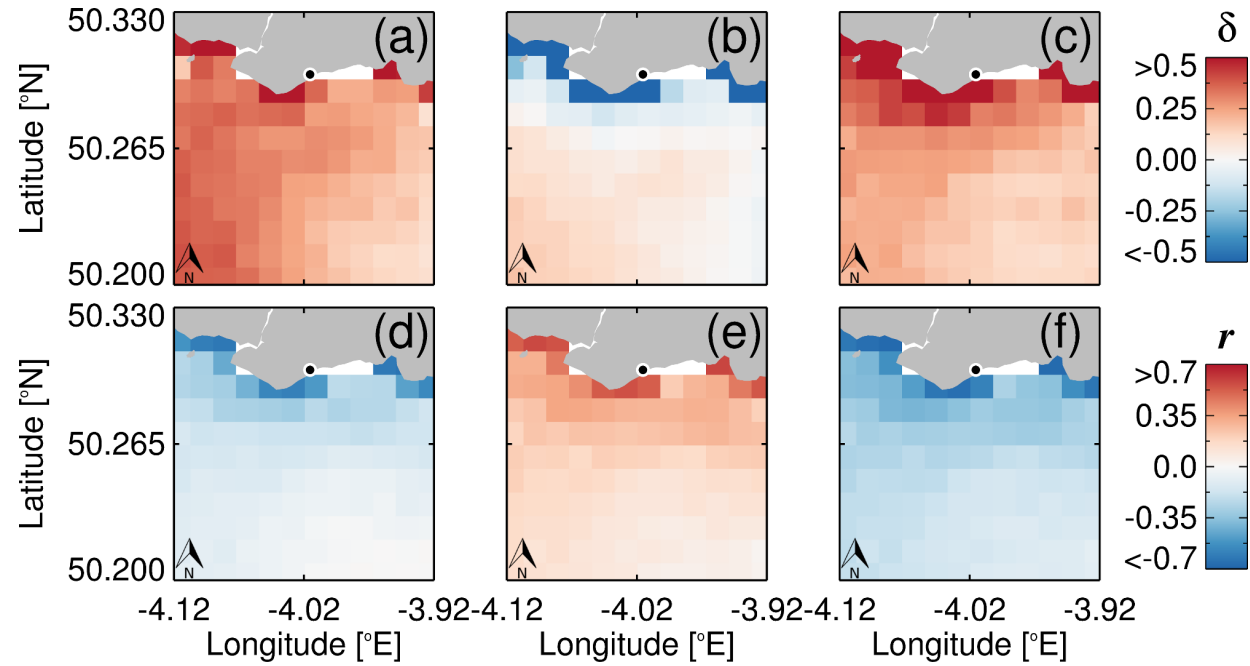

Figure 7. (a) Spatial maps (per-pixel) of the mean bias $(\delta)$ between $\mathrm{AVHHR} \mathrm{SST}_{N}$ data and in situ kelp site data (within $\pm 1 \mathrm{~h}$ ) during the day (solar zenith angle $<90^{\circ}$ ); (b) during the night (solar zenith angle $>90^{\circ}$ ); and (c) the difference between $(\mathbf{a}, \mathbf{b})$, i.e., day $\delta$ minus night $\delta$; (d) shows per-pixel Pearson correlations $(r)$ between solar zenith angle and the differences between satellite AVHRR SST $_{N}$ data and in situ temperature from the kelp site; (e) the same as (d) but using land surface temperature (LST) rather than solar zenith angle; (f) the same as (d) but using SST (kelp site) minus LST, rather than solar zenith angle.

\section{Results and Discussion}

\subsection{In Situ Comparison}

The in situ water temperature time-series from the kelp site was found to be in good agreement with SST observations from the three independent in situ datasets, at both short term (e.g., events) 
and longer term (e.g., seasonal) temporal scales. Between $93 \%$ to $95 \%$ of the of the variance in the kelp site data was explained by either of the three in situ datasets (Figure 1). The temperature data from the kelp site tracked the observations from the surfers at the two nearby beaches and at Station L4 tightly (Figure 1b,c), with slightly better agreement at lower temperatures (during winter) and a small systematic difference at warmer temperature (during summer) and during periods of intense warming (e.g., Figure 1d around August 2014). This perhaps reflected temperature gradients in the top $3 \mathrm{~m}$ of the water column, i.e., between the depth of the logger deployed at the kelp site and the top $1 \mathrm{~m}$ measured by the surfers and at L4. Systematic differences between surfer-collected data and the kelp site were relatively low $\left(\delta=-0.34^{\circ} \mathrm{C}\right.$, Figure 1c), especially when considering the accuracy of the Tidbit sensors $\left(\sim 0.2^{\circ} \mathrm{C}\right)$ and the spatial separation between sites (both vertically and horizontally). Better agreement is seen between the data logger at the kelp site and Station L 4 data $\left(\delta=-0.15^{\circ} \mathrm{C}\right)$, with lower root mean square errors $\left(0.53^{\circ} \mathrm{C}\right.$, Figure 1e) than the comparison with the surfer data $\left(0.81^{\circ} \mathrm{C}\right.$, Figure $\left.1 \mathrm{c}\right)$, though the number of concurrent match-ups at L4 far exceeded the match-ups from the surfers (13,982 compared with 238 , respectively).

We observed a systematic difference between data from the kelp site and data from Station E1 $\left(\delta=-0.60^{\circ} \mathrm{C}\right.$, Figure $\left.1 \mathrm{f}, \mathrm{g}\right)$ reflecting a gradient in temperature between the coastline and E1 which was in agreement with the three-year AVHRR SST $_{N}$ composite (Figure 1a). Unbiased root mean square errors $(\Delta)$ between data from Station E1 and the kelp site $\left(\Delta=0.69^{\circ} \mathrm{C}\right)$ lie in the range observed for the comparisons at Station L4 and with the surfer measurements $\left(\Delta=0.50\right.$ to $0.74{ }^{\circ} \mathrm{C}$, Figure $\left.1 \mathrm{c}, \mathrm{e}, \mathrm{g}\right)$. These statistical results are similar to those found when comparing the two oceanographic buoys with each other and with the surfer measurements see Figure 5 of [30]. When considering the spatial separation between sites, good agreement between the kelp site data and the three independent in situ SST datasets lends support to subsequent use of kelp site data for evaluating AVHRR SST data at the coastline. However, we acknowledge temperature differences between $1 \mathrm{~m}$ and $3 \mathrm{~m}$ depth at the coastline can occur, and future efforts should focus on correcting for these differences (e.g., by collecting profiles of surface temperature at the kelp site), which will depend on factors like: tidal strength, waves, wind, stratification, upwelling and coastal currents.

\subsection{Validation of AVHRR Data}

Figure 2 shows a comparison of the AVHRR $\operatorname{SST}_{N}$ data with the in situ data at the kelp site, L4, and E1, and Table 1 shows results for statistical tests on match-ups (within $\pm 1 \mathrm{~h}$ ) at the three sites for both $\mathrm{SST}_{N}$ and $\mathrm{SST}_{P}$ data. At the two offshore stations (L4 and E1), there is very good agreement between the AVHRR data (both $\mathrm{SST}_{N}$ and $\mathrm{SST}_{P}$ ) and the in situ measurements (Figure 2d-g, Table 1). Satellite observations track tightly variations in the in situ data at L4 and E1, with the AVHRR data explaining $>95 \%$ of the variance in the in situ data at L4 and E1, with a very low biases $\left(\delta \sim 0.00{ }^{\circ} \mathrm{C}\right)$, and low errors ( $\Psi$ and $\Delta \leq 0.55^{\circ} \mathrm{C}$ ), comparable to previous validations in the region [30] and global evaluations of AVHRR SST data in offshore waters [28].

However, when compared with the comparison at L4 and E1, the agreement between in situ and AVHRR (both $\mathrm{SST}_{N}$ and $\mathrm{SST}_{P}$ ) at the kelp site is not as good. The satellite observations do not follow the in situ data tightly over the course of the time-series (Figure $2 b$ ) and statistical tests between match-ups (Figure 2c) suggest AVHRR data explains only up to $83 \%$ of the variance in the in situ data, with a systematic negative bias $\left(\delta=-0.30\right.$ to $\left.-0.39^{\circ} \mathrm{C}\right)$, and higher errors $\left(\Psi=1.30\right.$ to $1.35^{\circ} \mathrm{C}$, $\Delta=1.27$ to $1.29^{\circ} \mathrm{C}$, Figure $3 \mathrm{c}$, Table 1 ). The results indicate a degradation in the performance of the AVHRR data at the coastline, when compared with Station L4 and E1, in agreement with the findings from Brewin et al. [30]. 
Table 1. Statistical tests between in situ SST data and AVHRR $\mathrm{SST}_{N}$ and $\mathrm{SST}_{P}$ products, at three sites (L4, E1 and the kelp site). For comparison, the equivalent statistics are provided from the Brewin et al. [30] study for AVHRR SST $P$ products and in situ SST collected by surfers in the nearshore (see their Figure $7 \mathrm{~b}$ at $\pm 3 \mathrm{~h}$ difference), acknowledging a slightly different match-up method was used in their study see Section 2.5 .3 of [30].

\begin{tabular}{cccccccc}
\hline \multirow{2}{*}{ Statistical Tests } & \multicolumn{2}{c}{ L4 } & \multicolumn{2}{c}{ E1 } & \multicolumn{2}{c}{ Kelp Site } & Brewin et al. [30] \\
& $\mathbf{S S T}_{\boldsymbol{N}}$ & $\mathbf{S S T}_{\boldsymbol{P}}$ & $\mathbf{S S T}_{\boldsymbol{N}}$ & $\mathbf{S S T}_{\boldsymbol{P}}$ & $\mathbf{S S T}_{\boldsymbol{N}}$ & $\mathbf{S S T}_{\boldsymbol{P}}$ & SST $_{\boldsymbol{P}}$ \\
\hline$r^{2}$ & 0.95 & 0.95 & 0.97 & 0.96 & 0.83 & 0.82 & 0.89 \\
$\Psi$ & 0.55 & 0.55 & 0.48 & 0.52 & 1.30 & 1.35 & 1.12 \\
$\Delta$ & 0.55 & 0.55 & 0.48 & 0.52 & 1.27 & 1.29 & 1.05 \\
$\delta$ & 0.01 & -0.02 & 0.01 & -0.02 & -0.30 & -0.39 & -0.39 \\
$N$ & 646 & 642 & 874 & 871 & 691 & 703 & 14 \\
\hline
\end{tabular}

Maps of statistical tests for the validation of AVHRR SST $_{N}$ at each site (Figure 3) demonstrate better performance for pixels closer to each site (higher $r^{2}$, lower $\Psi$, lower $\Delta$ and biases $(\delta)$ close to zero), typically for a radius of 5 pixels around the site, though not always circular (e.g., at L4). At the coastline, whereas the closest pixel to the kelp site showed high errors (Figure 2b,c and Table 1), two or three pixels offshore the performance in the AVHRR data improves dramatically, with higher $r^{2}$, lower $\Psi$, and lower $\Delta$ (Figure 4). Though the statistical performance at the pixel closest to the kelp site is similar between $\mathrm{SST}_{N}$ and $\mathrm{SST}_{P}$ products, there is better performance in the $\mathrm{SST}_{N}$ products in the pixels just offshore of the kelp site. This result is possibly an artifact of the $17.5 \mathrm{~km}$ square smoothing filter $(H)$ used in the computation of $\mathrm{SST}_{P}$ and suggests $\mathrm{SST}_{N}$ products, which treat the retrievals of SST independent for a given pixel, are perhaps more appropriate to use in nearshore coastal waters (acknowledging negligible differences between products in the validations in offshore waters at L4 and E1, see Table 1).

\subsection{Understanding Differences between Satellite and In Situ SST Data at the Coastline}

Differences between satellite (SST ${ }_{N}$ ) and in situ SST data at the closest pixels to the sites were correlated with a range of atmospheric variables, LST data and auxiliary datasets (Table 2). In general, at L4 and E1, there were found to be either no significant relationships, or very weak (but significant) relationships. At L4, differences between satellite $\left(\mathrm{SST}_{N}\right)$ and in situ SST data were weakly inversely correlated with solar zenith angle $(r=-0.15)$ and positively correlated with air temperature $(r=0.18)$. At E1, differences between satellite $\left(\mathrm{SST}_{N}\right)$ and in situ SST data were weakly inversely correlated with relative humidity $(r=-0.12)$ and weakly positively correlated with LST $(r=0.15)$. These results suggest that in offshore waters (at E1 and L4), the main sources of differences between satellite $\left(\mathrm{SST}_{N}\right)$ and in situ SST data are not likely related to the variables tested here (Table 2).

However, at the coastline (kelp site), differences between satellite and in situ SST were well correlated with a number of variables we tested (Table 2 and Figure 5). Whereas no significant relationships were found between these differences and time of year, air pressure, wind speed, wind direction, or the three atmospheric gases $\left(\mathrm{CO}_{2}, \mathrm{SO}_{2}\right.$ and $\left.\mathrm{CH}_{4}\right)$, significant relationships were found with hour of day, solar zenith angle, air temperature, relative humidity (weak correlation), LST, and air temperature minus LST, with the highest correlation found with the SST minus LST (Table 2 and Figure 5). During the night, when solar zenith angles were high, the satellite SST data were found to be systematically lower than the in situ SST (see Figure 5, and also Figure 7b), whereas during the day when solar zenith angles were low, the satellite SST data was found to be systematically higher than the in situ SST (see Figure 5, and also Figure 7a). 
Table 2. Correlations between a range of variables and the differences in SST between AVHRR SST and in situ SST data at three sites (L4, E1 and the kelp site). Bold indicates significant correlations $(p<0.001)$.

\begin{tabular}{ccccccc}
\hline Variables & \multicolumn{2}{c}{ L4 } & \multicolumn{2}{c}{ E1 } & \multicolumn{2}{c}{ Kelp Site } \\
& $\boldsymbol{r}$ & $\boldsymbol{p}$ & $\boldsymbol{r}$ & $\boldsymbol{p}$ & $\boldsymbol{r}$ & $\boldsymbol{p}$ \\
\hline Solar Zenith Angle & $-\mathbf{0 . 1 5}$ & $<\mathbf{0 . 0 0 1}$ & -0.07 & 0.053 & $-\mathbf{0 . 5 0}$ & $<\mathbf{0 . 0 0 1}$ \\
Air Temperature & $\mathbf{0 . 1 8}$ & $<\mathbf{0 . 0 0 1}$ & 0.05 & 0.206 & $\mathbf{0 . 3 1}$ & $<\mathbf{0 . 0 0 1}$ \\
LST & 0.01 & 0.621 & $\mathbf{0 . 1 5}$ & $<\mathbf{0 . 0 0 1}$ & $\mathbf{0 . 5 2}$ & $<\mathbf{0 . 0 0 1}$ \\
Relative Humidity & -0.11 & 0.008 & $\mathbf{- 0 . 1 2}$ & $<\mathbf{0 . 0 0 1}$ & $-\mathbf{0 . 1 4}$ & $<\mathbf{0 . 0 0 1}$ \\
Air Pressure & -0.04 & 0.336 & 0.06 & 0.080 & 0.10 & 0.008 \\
Wind Speed & -0.02 & 0.657 & 0.02 & 0.561 & 0.06 & 0.146 \\
$\mathrm{CO}_{2}$ & -0.09 & 0.080 & 0.02 & 0.700 & -0.13 & 0.006 \\
$\mathrm{SO}_{2}$ & 0.05 & 0.267 & 0.09 & 0.018 & 0.01 & 0.806 \\
$\mathrm{CH}_{4}$ & 0.06 & 0.290 & 0.07 & 0.097 & 0.00 & 0.954 \\
\hline
\end{tabular}

Considering the heat capacities of air and land are much lower than that of water, results suggest that differences between satellite and in situ SST data at the pixels closest to the coastline are related primarily to variations between LST and SST. Furthermore, although air temperature and LST were well correlated $(r=0.79, p<0.001$ for datasets used here see also [62]) and heat and cool faster than the sea, we observed a significant positive correlation between air temperature minus LST and solar zenith angle for the match-ups $(r=0.80, p<0.001)$, suggesting for clear skies that the land surface warms and cools at a faster rate than the air at the coastline of Plymouth, possibly related to the marine origin of the air mass (though depending on wind direction). Consistent with this, we observed a significant inverse relationship between air temperature minus LST and the differences between satellite and in situ SST (Figure 5), again suggesting it is the land surface that is impacting satellite SST retrievals at the coastline.

During the night (at high sun zenith angles), the land cools faster than the ocean, and, during the day (low sun zenith angles), the land warms faster than the ocean. If a sea pixel close to the coastline contains land, or is adjacent to land, one may expect the thermal signature from the land to impact the sea pixel, causing the satellite SST estimate to be lower at night and warmer during the day (as seen in Figure 5, see also Figure 7a,b). This will likely be intensified or dampened by factors such as diurnal fluctuations in solar radiation, tides, atmospheric conditions and their variability over the day, and the emissivity of the land.

To verify these findings, we also plotted the difference between SST at the kelp site and at L4 as a function of decimal hour of day, solar zenith angle and land temperature, for both the in situ and the satellite datasets separately (Figure 6). For the in situ comparison, we observed no significant relationships between SST differences at the sites and decimal hour of the day, and very weak (but significant) relationships with solar zenith angle and land temperature, possibly related to differences in the depth of sampling (lower solar zenith angle and higher land temperatures likely indicative of hot days that may have heated the top $1 \mathrm{~m}$ (L4) more than at $3 \mathrm{~m}$ depth (kelp site)). For the satellite data, however, we observed strong correlations between SST differences at the sites and all variables (Figure 6), and the correlations with solar zenith angle and land temperature were inverse to that observed in situ. During the night (at high sun zenith angles, cooler land) the satellite SST at the kelp site was seen to be cooler than at L4, whereas, during the day (low sun zenith angles, warmer land), the satellite SST at the kelp site was warmer than at L4.

To investigate these features at a broader spatial scale, we plotted systematic differences $(\delta)$ between satellite and in situ SST data for pixels surrounding the kelp site (assuming the in situ SST data at the kelp site is representative of the area) for the daytime match-ups (Figure 7a), for the night time match-ups (Figure 7b), and also plotted the difference between day and night (Figure 7c), to see the range in these biases from day to night. These differences are clearly the highest for the pixels close to the coastline (Figure $7 \mathrm{a}-\mathrm{c}$ ) and reduce for pixels further offshore. We also performed pixel-by-pixel 
correlations between the difference between satellite and in situ SST data and solar zenith angle (Figure 7d), LST (Figure 7e), and SST minus LST (Figure 7f). Again, these correlations were found to be highest at the pixels closer to the coastline. This supports the hypothesis that thermal contamination by land is impacting the retrieval of SST at the coastline. This could be either from land directly within the pixel, likely influenced by errors in geo-location, or possibly through thermal adjacency effects.

\subsection{Forward Outlook}

Given the thermal complexity of nearshore coastal waters and the lack of available in situ data to verify satellite retrievals of SST, it has been the policy of space agencies to flag nearshore SST data as erroneous and disregard it. However, the nearshore environment is one of the most valuable regions to society and particularly vulnerable to climate change. Coastal marine ecosystems support high levels of productivity [5] and biodiversity [3], contain many socioeconomically important species [63], and provide a wide range of ecosystem services [64]. Coastal systems are also amongst the most dynamic of marine environments, requiring monitoring systems that are capable of catching high spatial and temporal variability. Satellite remote sensing can help towards meeting these requirements. However, to do so requires new techniques to improve SST satellite retrievals in nearshore.

Consistent with previous studies that have attempted to validate satellite SST data in the nearshore [29-31], results from this study confirm higher uncertainty in satellite SST retrievals in nearshore waters, when compared with offshore waters. When comparing differences between satellite and in situ SST data at the coastline with a range of other environmental data, results suggest land contamination is a key factor contributing to this uncertainty. Thus, when developing new methods for retrieving SST from satellites in the nearshore, efforts should be focused on correcting the effect of land contamination in the nearshore pixels. Other factors related to coastal waters not investigated here that might impact satellite SST retrievals (e.g., floating kelp and optically-complex coastal waters) are also worthy of further investigation $[65,66]$.

Teggi and Despini [67] recently applied a Sharpening Water Thermal Imagery (SWTI) method [68] to satellite MODIS $1 \mathrm{~km}$ thermal imagery, in order to improve the resolution and coverage of near-shore MODIS SST data. As input, the method requires cover fractions (of land and water) and a perpendicular vegetation index obtained from MODIS images in the Visible-Near Infrared bands at a spatial resolution of $250 \mathrm{~m}$. Owing to a lack of in situ SST data, this technique was verified using two MODIS images that were concurrent with images from a higher-resolution thermal satellite on MODIS called ASTER [69]. The bias $(\delta)$ and the unbiased deviation $(\Delta)$ between satellite images were 0.45 and $0.88 \mathrm{~K}$, respectively. Other promising approaches have also been attempted in Lakes [70]. Though currently limited by infrequent overpasses, integrating high spatial resolution thermal observations (e.g., from Landsat and ASTER or from aircraft platforms) with the courser resolution AVHRR data could improve our understanding of the AVHHR nearshore retrievals and aid further algorithm development.

However, to verify and improve upon methods such as SWTI requires a radical increase in the spatial and temporal sampling of in situ SST data in the nearshore. Here, we have demonstrated the value of using loggers deployed and maintained in shallow subtidal habitats, which allowed for a high number of match-ups with satellite-derived SST. Integrating these observations with other developing in situ techniques, such as citizen science [30-33,35], the tagging of marine vertebrates with sensors [71], coastal gliders [72] and autonomous beach buoy systems [73,74], may significantly enhance the spatial and temporal sampling of in situ data in the nearshore, and improve operational satellite SST retrievals.

Whereas our analysis has focused on AVHRR, we acknowledge many other operational satellite SST products are available, for instance, through NASA (MODIS and VIIRS), EUMETSAT (Sentinel-3) and through Copernicus (multi-sensor SST products). Future work should also consider multi-product evaluations in nearshore waters. As satellite SST products are restricted to the surface layer of the ocean, they are not always suitable for inferring temperature variations beneath the surface and below the upper mixed-layer [75]. At these depths, other factors can influence water temperature e.g., internal 
waves [75]. Future efforts to improve subsurface temperature observations in coastal waters should also be taken.

\section{Conclusions}

We used three years of in situ water temperature measurements collected using a temperature logger (recording every $30 \mathrm{~min}$ ) located at the coastline of Plymouth in the UK (in a subtidal kelp forest $\sim 3 \mathrm{~m}$ below chart datum) to evaluate the performance of operational AVHRR SST products at the coastline. The data from the kelp site compared well with three independent in situ SST datasets collected in the nearby region over the same time-period (two offshore autonomous buoys and an SST dataset collected at two nearby beaches by surfers), with differences primarily related to the spatial separation among sites. The in situ SST measurements collected from the kelp site and the two autonomous buoys were matched with operational AVHRR SST passes with a time difference of $<1 \mathrm{~h}$. Extracting AVHRR SST data from the closest satellite pixel to the three sites and comparing this data quantitatively with the in situ datasets revealed a significant reduction in the performance of AVHRR at retrieving SST at the coastline, with root mean square differences twice as high at the kelp site as at the two offshore buoys, consistent with the prior study using surfer-derived in situ SST data for validation [30]. We found the performance of the AVHRR SST data at the coastline improved significantly when moving two to three pixels offshore, particularly for SST algorithms that treat each pixel independently in the retrieval process.

Differences between satellite and in situ SST data were correlated with a suite of atmospheric variables and a high temporal resolution land surface temperature dataset. At the coastline, we found that differences between satellite and in situ SST were well correlated with land surface temperature and solar zenith angle. Results suggest thermal contamination of the satellite pixel at the coastline by land is the principal cause of the large root mean square differences observed in the validation at the coastline, when compared with the validation offshore. The cause of this contamination is likely related to land directly within the pixel, perhaps linked to errors in geo-location, or possibly through thermal adjacency effects. Our results highlight key issues with retrievals of SST at the coastline and demonstrate the value of using in situ data obtained from marine ecological studies for evaluating satellite SST data in coastal regions.

Author Contributions: Conceptualization, R.J.W.B., D.A.S. and P.J.M.; Methodology, R.J.W.B., D.A.S., P.I.M., B.H.T., T.J.S., J.R.F. and M.Y.; Software, R.J.W.B., P.I.M. and B.H.T.; Validation, R.J.W.B.; Formal Analysis, R.J.W.B.; Investigation, R.J.W.B., D.A.S., P.J.M. and G.D.; Resources, R.J.W.B., D.A.S., P.I.M., B.H.T., T.J.S., J.R.F. and M.Y.; Data Curation, R.J.W.B., D.A.S., P.I.M., B.H.T., T.J.S., J.R.F. and M.Y.; Writing-Original Draft Preparation, R.J.W.B.; Writing—Review and Editing, R.J.W.B., D.A.S., P.J.M., G.D., P.I.M., B.H.T., T.J.S., J.R.F. and M.Y.

Funding: This research was funded by Plymouth Marine Laboratory and the UK National Environment Research Council (NERC) National Centre for Earth Observation. D.S. is supported by an Independent Research Fellowship awarded by NERC (NE/K008439/1).

Acknowledgments: We thank the NERC Earth Observation Data Acquisition and Analysis Service (NEODAAS) for the AVHRR imagery. We acknowledge the Copernicus Global Land Service for providing LST products. We acknowledge all surfers involved in collection of the SST data and all divers involved in the deployments of the kelp tags. We also acknowledge all those involved with data collection at Penlee Point Atmospheric Observatory (PPAO) and those maintaining and operating the L4 and E1 buoys. This is contribution No. 5 from the PPAO.

Conflicts of Interest: The authors declare no conflict of interest.

\section{Appendix A}

The following univariate statistical tests were used in our study.

\section{Appendix A.1. Pearson Correlation Coefficient ( $r$ )}

The Pearson correlation coefficient $r$ (also called Pearson's product moment correlation) was calculated according to 


$$
r=\frac{1}{N-1} \sum_{i=1}^{N}\left[\frac{X_{i}^{M}-\left(\frac{1}{N} \sum_{j=1}^{N} X_{j}^{M}\right)}{\left\{\frac{1}{N-1} \sum_{k=1}^{N}\left[X_{k}^{M}-\left(\frac{1}{N} \sum_{l=1}^{N} X_{l}^{M}\right)\right]^{2}\right\}^{1 / 2}}\right]\left[\frac{X_{i}^{E}-\left(\frac{1}{N} \sum_{m=1}^{N} X_{m}^{E}\right)}{\left\{\frac{1}{N-1} \sum_{n=1}^{N}\left[X_{n}^{E}-\left(\frac{1}{N} \sum_{o=1}^{N} X_{o}^{E}\right)\right]^{2}\right\}^{1 / 2}}\right]
$$

where $X$ is the variable and $N$ is the number of samples. The superscript $E$ denotes the estimated variable (e.g., from the AVHRR satellite sensor) and the superscript $M$ denotes the measured variable (e.g., measured in situ). Note that the Pearson correlation coefficient assumes a linear relationship between variables and normal distributions. The correlation coefficient may take any value between -1.0 and 1.0 .

\section{Appendix A.2. Coefficient of Determination $\left(r^{2}\right)$}

The coefficient of determination $\left(r^{2}\right)$ was taken to be the square of the Pearson correlation coefficient (i.e., Equation $\left.(\mathrm{A} 1)^{2}\right)$. The squared correlation coefficient may take any value between 0 and 1.0, with 1.0 indicating the estimated variable explains $100 \%$ of the variability in the measured variable.

Appendix A.3. Root Mean Square Difference ( $\Psi)$

The absolute Root Mean Square Difference ( $\Psi$ ) was calculated according to

$$
\Psi=\left[\frac{1}{N} \sum_{i=1}^{N}\left(X_{i}^{E}-X_{i}^{M}\right)^{2}\right]^{1 / 2} .
$$

The Root Mean Square Difference $(\Psi)$ can be partitioned into the bias $(\delta)$ and centre-pattern (or unbiased) Root Mean Square Difference $(\Delta)$, representing the systematic difference (accuracy) and the random difference (precision) and between two variables, respectively.

Appendix A.4. The Bias ( $\delta$ )

The absolute bias was expressed according to

$$
\delta=\frac{1}{N} \sum_{i=1}^{N}\left(X_{i}^{E}-X_{i}^{M}\right)
$$

Appendix A.5. The Centre-Pattern Root Mean Square Difference $(\Delta)$

The absolute centre-pattern (or unbiased) Root Mean Square Difference $(\Delta)$ was expressed according to

$$
\Delta=\left(\frac{1}{N} \sum_{i=1}^{N}\left\{\left[X_{i}^{E}-\left(\frac{1}{N} \sum_{j=1}^{N} X_{j}^{E}\right)\right]-\left[X_{i}^{M}-\left(\frac{1}{N} \sum_{k=1}^{N} X_{k}^{M}\right)\right]\right\}^{2}\right)^{1 / 2}
$$

and describes the difference between an estimated and a measured variable, regardless of the average bias between the two.

\section{References}

1. Arias, A.H.; Menendez, M. Marine Ecology in a Changing World; CRC Press: Boca Raton, FL, USA, 2013.

2. Livingston, R.J. Climate Change and Coastal Ecosystems: Long-Term Effects Of Climate and Nutrient Loading on Trophic Organization; CRC Press: Boca Raton, FL, USA, 2014.

3. Tittensor, D.P.; Mora, C.; Jetz, W.; Lotze, H.K.; Ricard, D.; Berghe, E.V.; Worm, B. Global patterns and predictors of marine biodiversity across taxa. Nature 2010, 466, 1098-1101, doi:10.1038/nature09329. 
4. Bertocci, I.; Araújo, R.; Oliveira, P.; Sousa-Pinto, I. Potential effects of kelp species on local fisheries. J. Appl. Ecol. 2015, 52, 1216-1226, doi:10.1111/1365-2664.12483.

5. Duarte, C. Reviews and syntheses: Hidden forests, the role of vegetated coastal habitats in the ocean carbon budget. Biogeosciences 2017, 14, 301-310, doi:10.5194/bg-14-301-2017.

6. Newton, A.; Harff, J.; You, Z.J.; Zhang, H.; Wolanski, E. Sustainability of future coasts and estuaries: A synthesis. Estuar. Coast. Shelf Sci. 2016, 183, 271-274.

7. Airoldi, L.; Beck, M.W. Loss, status and trends for coastal marine habitats of Europe. Oceanogr. Mar. Biol. Annu. Rev. 2007, 35, 345-405,

8. Rabalais, N.N.; Turner, R.E.; Díaz, R.J.; Justić, D. Global change and eutrophication of coastal waters. ICES J. Mar. Sci. 2009, 66, 1528-1537, doi:10.1093/icesjms/fsp047.

9. Barbier, E.B. A global strategy for protecting vulnerable coastal populations. Science 2014, 345, 1250-1251.

10. Bulleri, F.; Chapman, M.G. The introduction of coastal infrastructure as a driver of change in marine environments. J. Appl. Ecol. 2010, 47, 26-35, doi:10.1111/j.1365-2664.2009.01751.x.

11. Harley, C.D.G.; Randall Hughes, A.; Hultgren, K.M.; Miner, B.G.; Sorte, C.J.B.; Thornber, C.S.; Rodriguez, L.F.; Tomanek, L.; Williams, S.L. The impacts of climate change in coastal marine systems. Ecol. Lett. 2006, 9, 228-241, doi:10.1111/j.1461-0248.2005.00871.x.

12. Wernberg, T.; Russell, B.D.; Moore, P.J.; Ling, S.D.; Smale, D.A.; Coleman, M.; Steinberg, P.D.; Kendrick, G.A.; Connell, S.D. Impacts of climate change in a global hotspot for temperate marine biodiversity and ocean warming. J. Exp. Mar. Biol. Ecol. 2011, 400, 7-16.

13. Ferreira, J.G.; Vale, C.; Soares, C.V.; Salas, F.; Stacey, P.E.; Bricker, S.B.; Silva, M.C.; Marques, J.C. Monitoring of coastal and transitional waters under the E.U. Water Framework Directive. Environ. Monit. Assess. 2007, 135, 195-216.

14. Bojinski, S.; Verstraete, M.; Peterson, T.; Richter, C.; Simmons, A.; Zemp, M. The concept of essential climate variables in support of climate research, applications, and policy. Bull. Am. Meteorol. Soc. 2014, 95, 1431-1443, doi:10.1175/BAMS-D-13-00047.1.

15. GCOS. Systematic Observation Requirements from Satellite-Based Data Products for Climate; Technical Report; World Meteorological Organisation (WMO): Geneva, Switzerland, 2011.

16. Wong, P.P.; Losada, I.J.; Gattuso, J.P.; Hinkel, J.; Khattabi, A.; McInnes, K.L.; Saito, Y.; Sallenger, A. Climate Change 2014: Impacts, Adaptation, and Vulnerability. Part A: Global and Sectoral Aspects; Contribution of Working Group II to the Fifth Assessment Report of the Intergovernmental Panel of Climate Change; Cambridge University Press: Cambridge, UK; New York, NY, USA, 2014; pp. 361-409.

17. Brown, E.; Colling, A.; Park, D.; Phillips, J.; Rothery, D.; Wright, J. Seawater: Its Composition, Properties and Behaviour; Butterworth-Heinemann: Oxford, UK, 1995.

18. Eppley, R.W. Temperature and phytoplankton growth in the sea. Fish. Bull. 1972, 70, 1063-1085.

19. Gillooly, J.F.; Brown, J.H.; West, G.B.; Savage, V.M.; Charnov, E.L. Effects of Size and Temperature on Metabolic Rate. Science 2001, 293, 2248-2251.

20. Portner, H.O. Climate variations and the physiological basis of temperature dependent biogeography: Systemic to molecular hierarchy of thermal tolerance in animals. Comp. Biochem. Physiol. Part A 2002, 132, 739-761,

21. Smale, D.A.; Taylor, J.D.; Coombs, S.H.; Moore, G.; Cunliffe, M. Community responses to seawater warming are conserved across diverse biological groupings and taxonomic resolutions. Proc. R. Soc. B Biol. Sci. 2017, 284, doi:10.1098/rspb.2017.0534.

22. Weiss, R.F. The solubility of nitrogen, oxygen and argon in water and seawater. Deep Sea Res. 1970, 17, 721-735.

23. Lee, K.; Tong, L.; Millero, F.J.; Sabine, C.L.; Dickson, A.G.; Goyet, C.; Park, G.H.; Wanninkhof, R.; Feely, R.A.; Key, R.M. Global relationships of total alkalinity with salinity and temperature in surface waters of the world's oceans. Geophys. Res. Lett. 2006, 33, doi:10.1029/2006GL027207.

24. Poloczanska, E.S.; Brown, C.J.; Sydeman, W.J.; Kiessling, W.; Schoeman, D.S.; Moore, P.J.; Brander, K.; Bruno, J.F.; Buckley, L.B.; Burrows, M.T.; et al. Global imprint of climate change on marine life. Nat. Clim. Chang. 2013, 3, 919-925, doi:10.1038/nclimate1958.

25. Vergés, A.; Steinberg, P.D.; Hay, M.E.; Poore, A.G.B.; Campbell, A.H.; Ballesteros, E.; Heck, K.L.; Booth, D.J.; Coleman, M.A.; Feary, D.A.; et al. The tropicalization of temperate marine ecosystems: Climate-mediated changes in herbivory and community phase shifts. Proc. R. Soc. B Biol. Sci. 2014, 281, doi:10.1098/rspb.2014.0846. 
26. Garrabou, J.; Coma, R.; Bensoussan, N.; Bally, M.; Chevaldonne, P.; Cigliano, M.; Diaz, D.; Harmelin, J.G.; Gambi, M.C.; Kersting, D.K.; et al. Mass mortality in Northwestern Mediterranean rocky benthic communities: Effects of the 2003 heat wave. Glob. Change Biol. 2009, 15, 1090-1103, doi:10.1111/j.1365-2486.2008.01823.x.

27. Wernberg, T.; Bennett, S.; Babcock, R.C.; de Bettignies, T.; Cure, K.; Depczynski, M.; Dufois, F.; Fromont, J.; Fulton, C.J.; Hovey, R.K.; et al. Climate-driven regime shift of a temperate marine ecosystem. Science 2016, 353, 169-172, doi:10.1126/science.aad8745.

28. Merchant, C.J.; Embury, O.; Roberts-Jones, J.; Fiedler, E.; Bulgin, C.E.; Corlett, G.K.; Good, S.; McLaren, A.; Rayner, N.; Morak-Bozzo, S.; et al. Sea surface temperature datasets for climate applications from Phase 1 of the European Space Agency Climate Change Initiative (SST CCI). Geosci. Data J. 2014, 1, 179-191, doi:10.1002/gdj3.20.

29. Smit, A.J.; Roberts, M.; Anderson, R.J.; Dufois, F.; Dudley, S.F.; Bornman, T.G.; Olbers, J.; Bolton, J.J. A coastal seawater temperature dataset for biogeographical studies: large biases between in situ and remotely-sensed data sets around the coast of South Africa. PLOS ONE 2013, 8, e81944, doi:10.1371/journal.pone.0081944.

30. Brewin, R.J.W.; de Mora, L.; Billson, O.; Jackson, T.; Russell, P.; Brewin, T.G.; Shutler, J.; Miller, P.I.; Taylor, B.H.; Smyth, T.J.; et al. Evaluating operational AVHRR sea surface temperature data at the coastline using surfers. Estuar. Coast. Shelf Sci. 2017, 196, 276-289, doi:10.1016/j.ecss.2017.07.011.

31. Brewin, R.J.W.; de Mora, L.; Jackson, T.; Brewin, T.G.; Shutler, J. On the potential of surfers to monitor environmental indicators in the coastal zone. PLOS ONE 2015, 10, e0127706.

32. Brewin, R.J.W.; Hyder, K.; Andersson, A.J.; Billson, O.; Bresnahan, P.J.; Brewin, T.G.; Cyronak, T.; Dall'Olmo, G.; de Mora, L.; Graham, G.; et al. Expanding aquatic observations through recreation. Front. Mar. Sci. 2017, 4, 351, doi:10.3389/fmars.2017.00351.

33. Bresnahan, P.J.; Wirth, T.; Martz, T.R.; Andersson, A.J.; Cyronak, T.; D’Angelo, S.; Pennise, J.; Melville, W.K.; Lenain, L.; Statom, N. A sensor package for mapping $\mathrm{pH}$ and oxygen from mobile platforms. Methods Oceanogr. 2016, 17, 1-13, doi:10.1016/j.mio.2016.04.004.

34. Hut, R.; Tyler, S.; van Emmerik, T. Proof of concept: Temperature-sensing waders for environmental sciences. Geosci. Instrum. Method. Data Syst. 2016, 5, 45-51, doi:10.5194/gi-5-45-2016.

35. Wright, S.; Hull, T.; Sivyer, D.B.; Pearce, D.; Pinnegar, J.K.; Sayer, M.D.J.; Mogg, A.O.M.; Azzopardi, E.; Gontarek, S.; Hyder, K. SCUBA divers as oceanographic samplers: The potential of dive computers to augment aquatic temperature monitoring. Sci. Rep. 2016, 6, 1-8, doi:10.1038/srep30164.

36. Smale, D.A.; Burrows, M.T.; Evans, A.J.; King, N.; Sayer, M.D.; Yunnie, A.L.; Moore, P.J. Linking environmental variables with regional-scale variability in ecological structure and standing stock of carbon within UK kelp forests. Mar. Ecol. Prog. Ser. 2016, 542, 79-95, doi:10.3354/meps11544.

37. Smale, D.A.; Moore, P.J. Variability in kelp forest structure along a latitudinal gradient in ocean temperature. J. Exp. Mar. Biol. Ecol. 2017, 486, 255-264, doi:10.1016/j.jembe.2016.10.023.

38. Smale, D.A.; Wernberg, T. Satellite-derived SST data as a proxy for water temperature in nearshore benthic ecology. Mar. Ecol. Prog. Ser. 2009, 387, 27-37, doi:10.3354/meps08132.

39. Stobart, B.; Mayfield, S.; Mundy, C.; Hobday, A.J.; Hartog, J.R. Comparison of in situ and satellite sea surface-temperature data from South Australia and Tasmania: How reliable are satellite data as a proxy for coastal temperatures in temperate southern Australia? Mar. Freshw. Res. 2016, 67, 612-625, doi:10.1071/MF14340.

40. Bailey, S.W.; Werdell, P.J. A multi-sensor approach for the on-orbit validation of ocean color satellite data products. Remote Sens. Environ. 2006, 102, 12-23, doi:10.1016/j.rse.2006.01.015.

41. Fletcher, S.; Saunders, J.; Herbert, R. A review of the ecosystem services provided by broad-scale marine habitats in England's MPA network. J. Coast. Res. 2011, 64, 378-383.

42. Maier, G.; Nimmo-Smith, R.J.; Glegg, G.A.; Tappin, A.D.; Worsfold, P.J. Estuarine eutrophication in the UK: Current incidence and future trends. Aquat. Conserv. Mar. Freshw. Ecosyst. 2009, 19, 43-56, doi:10.1002/aqc.982.

43. L'Hévéder, B.; Speich, S.; Ragueneau, O.; Gohin, F.; Bryère, P. Observed and projected sea surface temperature seasonal changes in the Western English Channel from satellite data and CMIP5 multi-model ensemble. Int. J. Climatol. 2016, 37, 2831-2849.

44. Frost, M.T.; Bayliss-Brown, G.; Buckley, P.; Cox, M.; Dye, S.R.; Sanderson, W.G.; Stoker, B.; Withers Harvey, N. A review of climate change and the implementation of marine biodiversity legislation in the United Kingdom. Aquat. Conserv. Mar. Freshw. Ecosyst. 2016, 26, 576-595, doi:10.1002/aqc.2628. 
45. Holt, J.; Schrum, C.; Cannaby, H.; Daewel, U.; Allen, I.; Artioli, Y.; Bopp, L.; Butenschon, M.; Fach, B.; Harle, J.; Pushpadas, D. Potential impacts of climate change on the primary production of regional seas: A comparative analysis of five European seas. Prog. Oceanogr. 2016, 140, 91-115, doi:10.1016/j.pocean.2015.11.004.

46. Fernandes, J.A.; Papathanasopoulou, E.; Hattam, C.; Queirós, A.M.; Cheung, W.W.; Yool, A.; Artioli, Y.; Pope, E.C.; Flynn, K.J.; Merino, G.; Calosi, P. Estimating the ecological, economic and social impacts of ocean acidification and warming on UK fisheries. Fish Fish. 2017, 18, 389-411, doi:10.1111/faf.12183.

47. Doney, S.C.; Lima, I.D.; Moore, J.K.; Lindsay, K.; Behrenfeld, M.J.; Westberry, T.K.; Mahowald, N.; Glover, D.M.; Takahashi, T. Skill metrics for confronting global upper ocean ecosystem-biogeochemistry models against field and remote sensing data. J. Mar. Syst. 2009, 76, 95-112, doi:10.1016/j.jmarsys.2008.05.015.

48. Brewin, R.J.W.; Sathyendranath, S.; Müller, D.; Brockmann, C.; Deschamps, P.Y.; Devred, E.; Doerffer, R.; Fomferra, N.; Franz, B.A.; Grant, M.; et al. The Ocean Colour Climate Change Initiative: III. A round-robin comparison on in-water bio-optical algorithms. Remote Sens. Environ. 2015, 162, 271-294, doi:10.1016/j.rse.2013.09.016.

49. Donlon, C. Sentinel-3 Mission Requirements Traceability Document (MRTD). Technical Report. Available online: http:/ / download.esa.int/docs/EarthObservation/GMES_Sentinel-3_MRTD_Iss-1_Rev-0-issuedsigned.pdf (accessed on 5 September 2017).

50. Smyth, T.J.; Fishwick, J.R.; Gallienne, C.P.; Stephens, J.A.; Bale, A.J. Technology, Design, and Operation of an Autonomous Buoy System in the Western English Channel. J. Atmos. Ocean. Technol. 2010, 27, 2056-2064, doi:10.1175/2010JTECHO734.1.

51. Minnett, P.J.; Barton, I.J. chapter Remote Sensing of the Earth's Surface Temperature. In Radiometric Temperature Measurements: II. Applications; Elsevier Inc.: New York, NY, USA, 2010; pp. 333-392.

52. Yang, M.; Bell, T.; Hopkins, F.; Kitidis, V.; Cazenave, P.; Nightingale, P.; Yelland, M.; Pascal, R.; Prytherch, J.; Brooks, I.; et al. Air-sea fluxes of $\mathrm{CO}_{2}$ and $\mathrm{CH}_{4}$ from the Penlee Point Atmospheric Observatory on the south-west coast of the UK. Atmos. Chem. Phys. 2016, 16, 5745-5761, doi:10.5194/acp-16-5745-2016.

53. Yang, M.; Bell, T.; Hopkins, F.; Smyth, T. Attribution of atmospheric sulfur dioxide over the English Channel to dimethyl sulfide and changing ship emissions. Atmos. Chem. Phys. 2016, 16, 4771-4783, doi:10.5194/acp-16-4771-2016.

54. Miller, P.; Groom, S.; McManus, A.; Selley, J.; Mironnet, N. PANORMA: A semi-automated AVHRR and CZCS system for observation of coastal and ocean processes. In Proceedings of the Remote Sensing Society Annual Conference, Observations and Interactions, Reading, UK, 2-4 September 1997.

55. Sandford, T.D.G.; Stephenson, J. Orbital prediction for the NOAA satellite series. In Proceedings of the Remote Sensing Society Annual Conference, Dundee, UK, 15-17 September 1992; pp. 424-433.

56. Bordes, P.; Brunel, P.; Marsouin, A. Automatic adjustment of AVHRR navigation. J. Atmos. Ocean. Technol. 1992, 9, 15-27.

57. Saunders, R.W.; Kriebel, K.T. An improved method for detecting clear sky and cloudy radiances from AVHRR data. Int. J. Remote Sens. 1988, 9, 123-150.

58. Thiermann, V.; Ruprecht, E. A method for detection of clouds using AVHRR infrared observations. Int. J. Remote Sens. 1992, 13, 1829-1841.

59. Roozekrans, J.N.; Prangsma, G.J. Processing and Application of Digital AVHRR Imagery for Land And Sea Surfaces; Final Report of BCRS Project No: TO-3.1 “Digital thermal imagery of land and sea surfaces". Technical Report; Royal Netherlands Meteorological Institute (KNMI): De Beert, The Netherlands, 1988.

60. Walton, C.C.; Pichel, W.G.; Sapper, J.F.; May, D.A. The Development and Operational Application of Nonlinear Algorithms for the Measurement of Sea Surface Temperatures with the NOAA Polar-Orbiting Environmental Satellites. J. Geophys. Res. 1998, 103, 27999-28012.

61. Barton, I.J. Digitization effects in AVHRR and MCSST data. Remote Sens. Environ. 1989, 29, 87-89.

62. Mildrexler, D.J.; Zhao, M.; Running, S.W. A global comparison between station air temperatures and MODIS land surface temperatures reveals the cooling role of forests. J. Geophys. Res. Biogeosci. 2011, 116, G03025, doi:10.1029/2010JG001486.

63. Stewart, K.R.; Lewison, R.L.; Dunn, D.C.; Borkland, R.H.; Kelez, S.; Halpin, P.N.; Crowder, L.B. Characterizing Fishing Effort and Spatial Extent of Coastal Fisheries. PLoS ONE 2010, 5, e14451, doi:10.1371/journal.pone.0014451.

64. Beaumont, N.J.; Austen, M.C.; Mangi, S.C.; Townsend, M. Economic valuation for the conservation of marine biodiversity. Mar. Pollut. Bull. 2008, 56, 386-396, doi:10.1016/j.marpolbul.2007.11.013. 
65. Cavalli, R.M. Retrieval of Sea Surface Temperature from MODIS Data in Coastal Waters. Sustainability 2017, 9, 2032, doi:10.3390/su9112032.

66. Cavalli, R.M. Comparison of Split Window Algorithms for Retrieving Measurements of Sea Surface Temperature from MODIS Data in Near-L and Coastal Waters. ISPRS Int. J. Geo-Inf. 2018, 7, 30, doi:10.3390/ijgi7010030.

67. Teggi, S.; Despini, F. Estimation of subpixel MODIS water temperature near coastlines using the SWTI algorithm. Remote Sens. Environ. 2014, 142, 122-130, doi:10.1016/j.rse.2013.11.011.

68. Teggi, S. A technique for spatial sharpening of thermal imagery of coastal waters and of water courses. Int. J. Remote Sens. 2012, 33, 3063-3089.

69. Matsuoka, Y.; Kawamura, H.; Sakaida, F.; Hosoda, K. Retrieval of high-resolution sea surface temperature data for Sendai Bay, Japan, using the Advanced Spaceborne Thermal Emission and Reflection Radiometer (ASTER). Remote Sens. Environ. 2011, 115, 205-213, doi:10.1016/j.rse2010.08.018.

70. Sentlinger, G.I.; Hook, S.J.; Laval, B. Sub-pixel water temperature estimation from thermal-infrared imagery using vectorized lake features. Remote Sens. Environ. 2008, 112, 1678-1688.

71. Fedak, M. Marine animals as platforms for oceanographic sampling: A "winwin" situation for biology and operational oceanography. Mem. Natl. Inst. Polar Res. 2004, 58, 133-147.

72. Rudnick, D.; Davis, R.E.; Eriksen, C.C.; Fratantoni, D.M.; Perry, M.J. Underwater gliders for ocean research. Mar. Technol. Soc. J. 2004, 38, 73-84.

73. Shively, D.A.; Nevers, M.B.; Breitenbach, C.; Phanikumar, M.S.; Przybyla-Kelly, K.; Spoljaric, A.M.; Whitman, R.L. Prototypic automated continuous recreational water quality monitoring of nine Chicago beaches. J. Environ. Manag. 2016, 166, 285-293, doi:10.1016/j.jenvman.2015.10.011.

74. Schmidt, W.; Raymond, D.; Parish, D.; Ashton, I.G.; Miller, P.I.; Campos, C.J.; Shutler, J.D. Design and operation of a low-cost and compact autonomous buoy system for use in coastal aquaculture and water quality monitoring. Aquac. Eng. 2018, 80, 28-36, doi:10.1016/j.aquaeng.2017.12.002.

75. Leichter, J.J.; Helmuth, B.; Fischer, A.M. Variation beneath the surface: Quantifying complex thermal environments on coral reefs in the Caribbean, Bahamas and Florida. J. Mar. Res. 2006, 64, 563-588, doi:10.1357/002224006778715711.

(C) 2018 by the authors. Licensee MDPI, Basel, Switzerland. This article is an open access article distributed under the terms and conditions of the Creative Commons Attribution (CC BY) license (http://creativecommons.org/licenses/by/4.0/). 